\title{
Analysis of Fuel-Bundle Radiographs Using Modeling
}

by

H. B. Demuth 
In the interest of prompt distribution, this report was not edited by the Technical Information staff.

This work was snonsored by the US EniêşY Rssearch and Develonment Administration under contract with Union Carbide Nuclear Divisior

Printed in the United States of America. Available from National Technical Inlormation Service

US Department of Commerce

5285 Port Royal Road

Springtiald, VA 22151

Price: Printed Copy \$4.00 Micratiche \$2.25

This report was prepared as an accaunt of work tponsored

b. The United Sigtes Government. Neither the Uniled Stated

nor the Ginited Statea Eneray Research and Development Ad-

ministration, nor any of their employees, nor sny of their con-

tractors, subcontractors, or their employees. mikes ony

warranty, express or implied, or asumes any lecal liahility or

retponaibility for the accuracy. completentesn, ar usefulnesi of

represernts :hat it: use would not infrinte privately owned

riebta. 


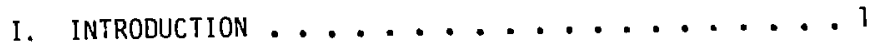

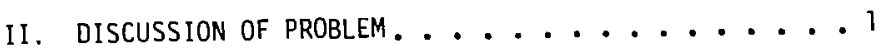
A. Objectives ................ 1
B. Fuel Rod Test Bundles and Radiographs..... 1
C. Ideal Gap and Degrading F.fiects....... 2




B. Model and Analysis .......... 2
C. Least-Squares Solution ......... 5

IV. RESULTS. ................ 6

A. Analytic lietnod and Its Application .... 6

B. Measurements ............ 7

v. CONCLUSIONS................... 10

A. Analytical Methods ......... 10

B. Fuel Bundle Gaps .......... 10

VI. FUTURE WORK. ................. 10

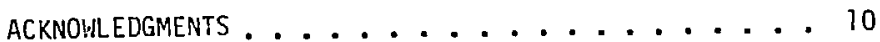

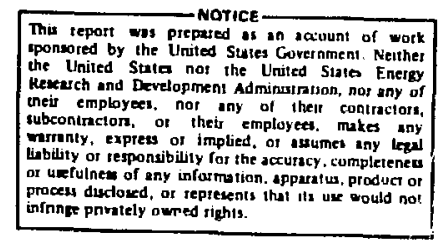

This teport was prepated of an satuun of wotk the United Stater kexcerch and Development Adminusirition, not any of unes employees, nor any of thetr contractors, ris. of theis employees. makes any urefur lesponsibuty far the accusacy, completenew

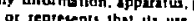

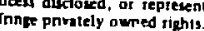

Appendi: A. Six Cases of Overlap .......... 11

B. Guide to the Batch Use of Least-Squares Program 13

I. Background .......... 13

II. Some Mathematical Formulations ..... 13

III. Some Illustrative Examples ..... 14

IV. Use of LSMFT ........... 14

C. Output From Least-Squares Program ..... 15 
ANALYSIS OF FUEL-BUNDLE RADIOGRAPHS USING MODELING

by

H. B. Demuth

\section{ABSTRACT}

It was desired to estimate the thicknf.ss of gaps imaged on highly degraded radiographs. A powerful ilathematical method for estimating gap widths was developed and applied. This report describes the problem, develops the techniques used to solve the problem, and presents results, conclusions, and suggestions for future work.

\section{IIITPODUCTION}

The Hol ifield National Laboratory (HNL) oresented the Los Alamos Scientific Laboratory (LASL) with 18 radiographs of fuel rod test bundles. The general problem is to estimate the thickness of the gap between some cylindrical rods and a flat b: 1 surface. The edges of the gaps are poorly defined due to finite source size, $x$-ray scatter, parallax, film grain noise, and other degrading effects.

The radiographs were scanned and the scan-line data were averaged to reduce noise and to convert the problem to one dimension. A model of the ideal gap convolved with an appropriate point-spread function was fit to the averaged data with a leastsquares program; and the gap width was determined from the final fitted-model parameters. The leastsquares routine dif converge and the gaps obtained are of reasonable size. The method is remarkably insersitive to noise.

This report describes the problem, the techniques used to solve $i t$, and the results and conclusions. Suggestions for future work are also given.

\section{DISCUSSION OF PROBLEA}

A. Objectives

The objectives of this work were threefold: first, to develop a new analytic method for measuring gaps in the HNL radiographs; second, to apply the method to representative radiographs to determine its effectiveness; and third, to find if there were indeed changes in the gaps due to assembly or heating. To achieve these objectives two radiographs would be studied in detail. Mechanical distortion, if present, would be expected to appear as a gradual change in gap width as one traveled the length of the gap.

8. Fuel Rod Test Bundles and Radiographs

A simplified picture of a fuel rod test bundle cross section is shown in Fig. 2-1. The two gaps of one bundle are imaged reasonably well in each radiograph. As shown in Fig. $2 \cdot .1$, the $x$-ray source is positioned "opposite" the right gap. The geometry is such that the parallax associated with the left gap is severe; and its effects are clearly discernible to the eye in exanining the radiographs.

A picture of a typical radiograph is snown in Fig. 2-2. Size reduction has obscured details but. Fig. 2-2 does convey some idea of 'he complexity of the overall object being imaged. The gans under study are obscured or overlaid with other objects in many places in the radiographs.

Some of the fuel bundles were radiographed when cold and presumably undistorted except through assembly. Other fuel bundles had been heated electrically, and anticipated interior distortions were 


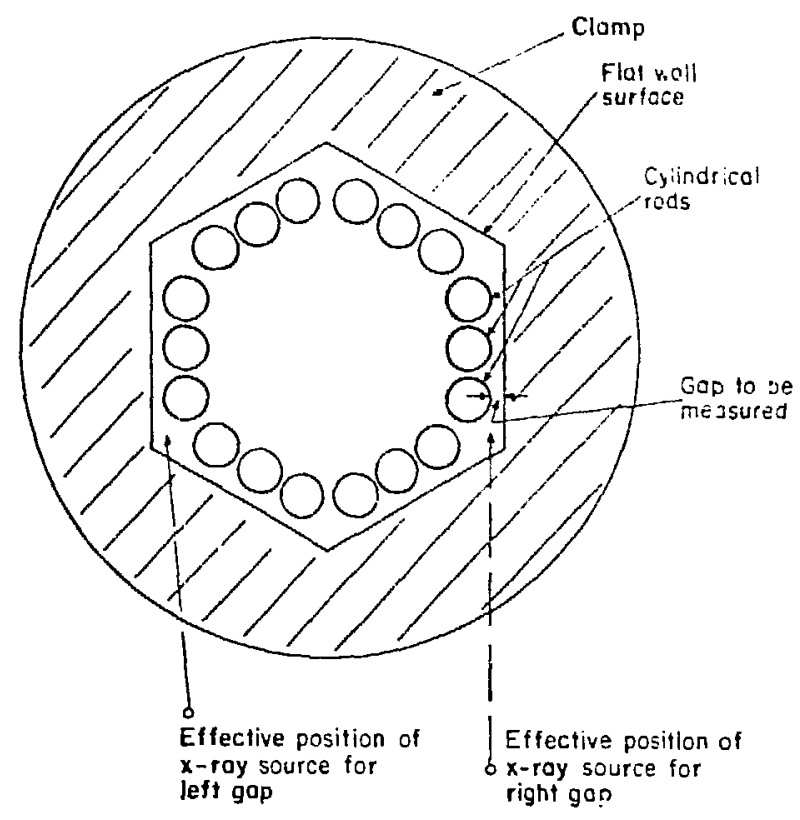

Fig. 2-1. Fuel rod test bundle cross section.

unknown. Of the 18 radiograprs, Numbers 2 and 5 were chosen as best examples for the work that we were to do. Neither fuel bundle had been heated and these two radiographs were among the best in quality. C. Ideal Gap and Degrading Effects

A profile of the ideal gap that one would see in the absence of all degrading effects is shown in Fig. 2-3a. This profile can be characterized by six parameters, $P_{1}$ through $P_{6}$. The difference $P_{4}-P_{2}$ defines the gap width.

As noted previously, the ideal gap is not imaged clearly for many reasons. First, there may be interference of other physical pieces that overlap the gap image in the radiograph. Second, the radiation source size is fairly large, and this causes blurring. Third, the interaction of Cobalt60 gamma rays and the fuel bundle will give some scatter and image blurring. Fourth, geometric (parallax) effects will cause still further blurring. The radiation source is parallel to the clamp and bundle on the right side but not on the left side; and there is considerable blurring of the edges of the left gap due to the off-set of the source. Fifth. film grain noise is significant in the radiographs and interferes with the interpretation of all details, gap included.
A Jifital scan across the (degraded gap as inlled in the radionraph might. typically qive a film censity profile like that shown in riq. 2-3b. Attempts have been made to cluess the lat widths from such data through "eyeballing" a fir. to the data; but the errors in such attempts were considerable. Basically, the data is very poor due to knowin (and perhaps unknown) effects; and some kind of noise reduction, restoration and powerful fitting liust be applied to eitract the gap edgcs.

1II. SOLUTION OF PROBLEM

A. Scanning

Each of the 18 radiogra,jhs was scanned at 26 stations as shown in Fig. 3-i. The vertical distance between stations on the ridiograph was chosen at $2.771 \mathrm{~cm}$ so that the distance between stations on the fuel bundle is $2.54 \mathrm{~cm}$. The 2.771 enhancement factor is the source-to-film distance $(152.4 \mathrm{~cm})$ divided by the source to test bundle distance $(139.7 \mathrm{~cm})$. An attempt to determine the enlargement factor by using tine $0.61-\mathrm{cml}$ holes in the upper right corner of each radiograph failed. Scans of these holes were noisy and had poorly defined edges.

Both gaps were scanned fron outside to inside. Thus, the abrupt edge of each gap occurs first as one goes from the beginning to the end of data associated with each gap. There are 500 points on each of the 100 lines scanned at each station. An aperture of 10 um was used.

The data of one scan line were very noisy. as shown in Fig. 3-2. To reduce noise, the 1001 ines of data at each scation were averaged. The averaged data were recorded on magnetic tape for use by HNL. Averaging reduced the noise considerably but did not eliminate it. A typical picture of averaged data is given in Fig. 3-3.

\section{B. Hold and Ar:a7ysis}

It is assumed that the radiograph gap profile can be described by an equation of the form

$$
g(x)=\int_{-\infty}^{\infty} h\left(x_{1}\right) f\left(x-x_{1}\right) d x_{1}+n(x),
$$

where $g$ is the (sampled data) profile recorded on film, $h$ is the point-spread function, $f$ is the "true" profile, and $n$ is the noise. Hopefully the noise is reduced by the averaging described previously. 


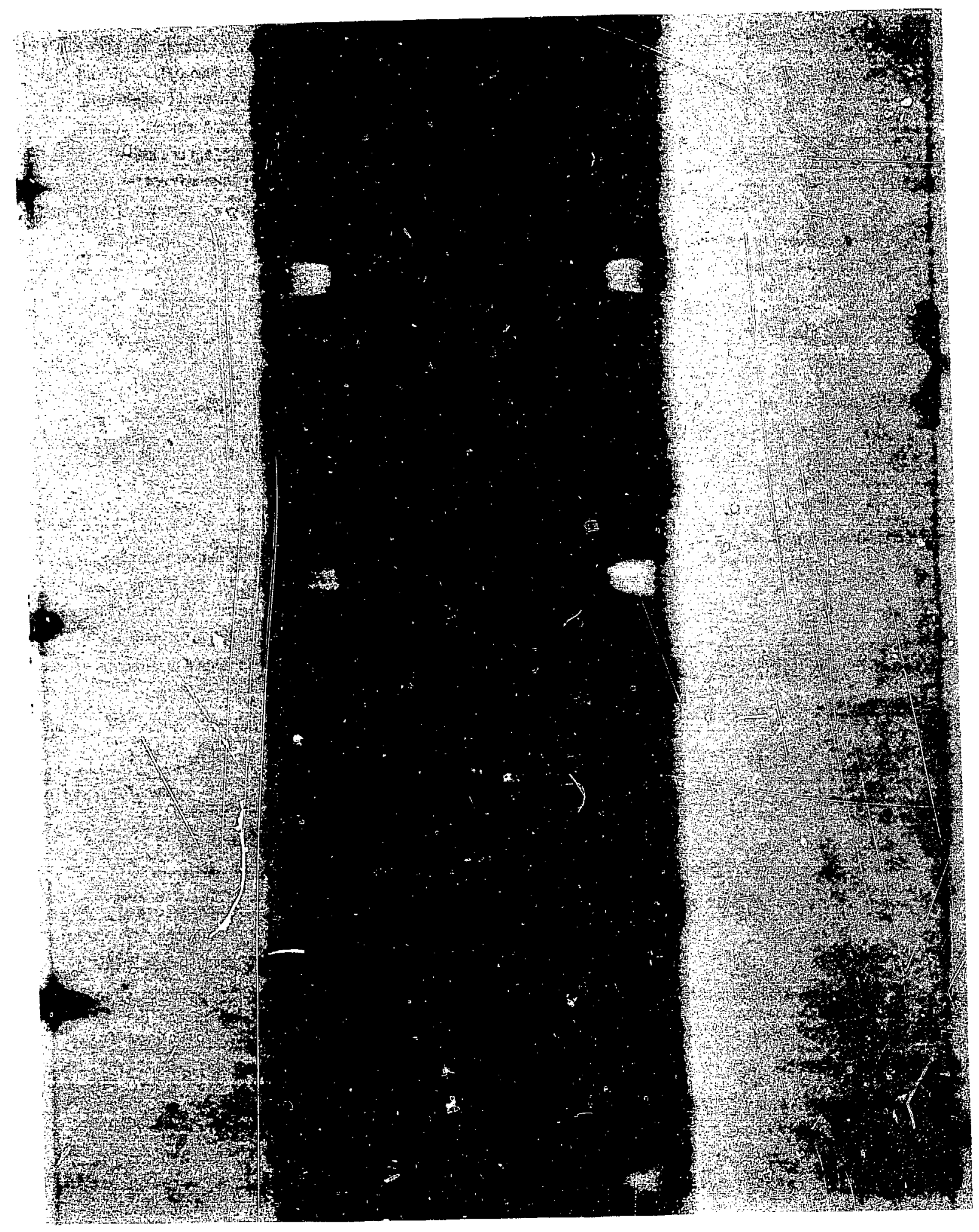

Fig. 2.2. Radiograph No. 2. 




a. Profile of ideal gap.

d. Profila $y^{2}$ ised ian.

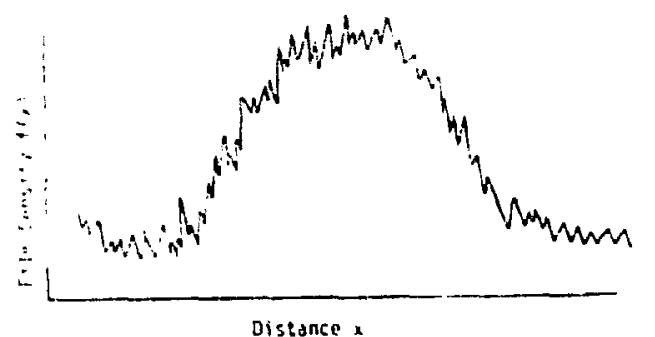

b. Protile of gap degraded by various effects.

:iq. 2-3. Profiles of ideal and actual gap.

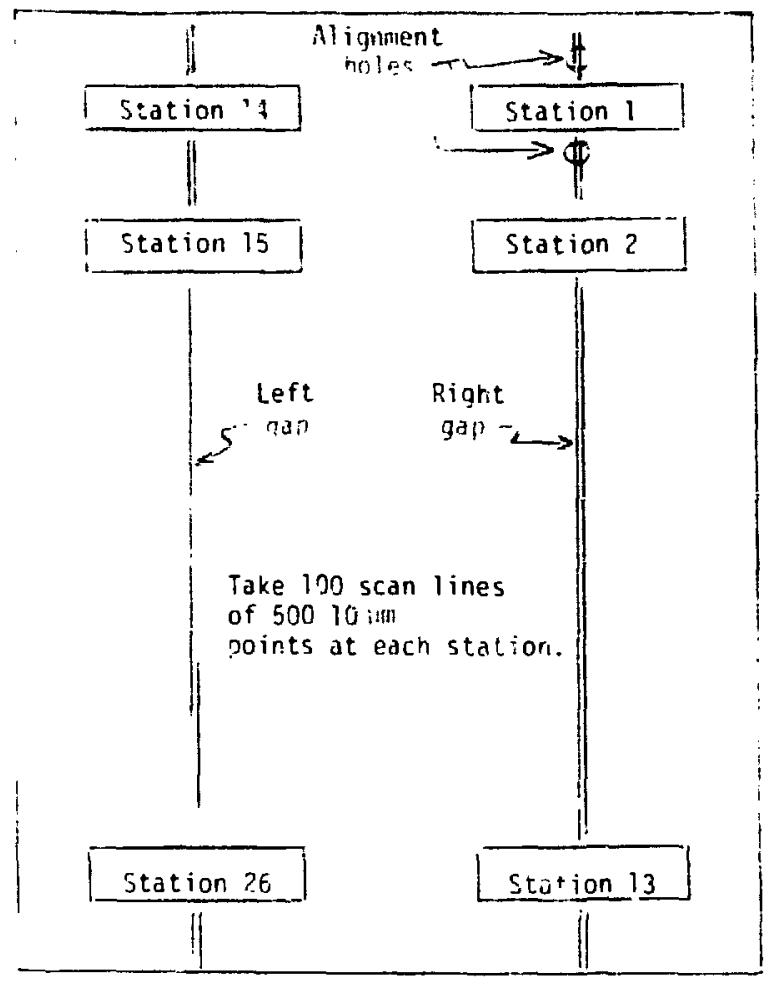

Fig. 3.1. Scan instructions for HNL radiouraphs.
Finite source size, electron scattering and parallax all contribute to the point-spread funition (PSF). A PSF whose shape is dependent only on finite sour:e size was chosen for this work. It is a circle with a diameter of approximately $0.0297 \mathrm{~cm}$. The data were averaged in one direction: and averaging the PSF in a similar way produces an $h(x)$ as shown below.

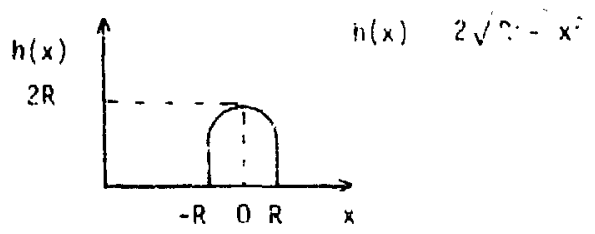

A. brief investigation of radiation scatter and parallax shows that it is easy to iustify a wider FSF: but fortunately, the gap widths are found not to depend critically on the width of the PSF.

The gap model used is shown below.

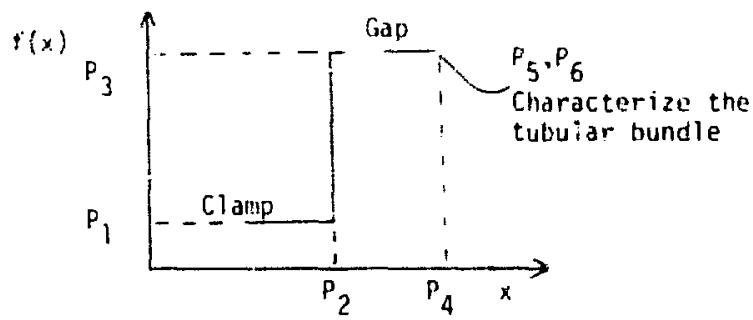

The parameters $P_{1}$ through $\bar{P}_{6}$ (and the PSF radius $R=P$, , if desired) are fit to the data $g(x)$ by a least-squares routine. $P_{5}$ and $P_{6}$ allow an arbitrary slope and quadratic term on the tail of the mondel.

Both $h$ and $f$ are expressible in analytic form. Thus, it was possible to integrate the right side of Eq. (3.1) to give a nonintegral equation

$$
q(x)=q\left(x, p_{1}, \ldots P_{7}\right) .
$$

The least-squares procedure was applied to all equation of this form. 


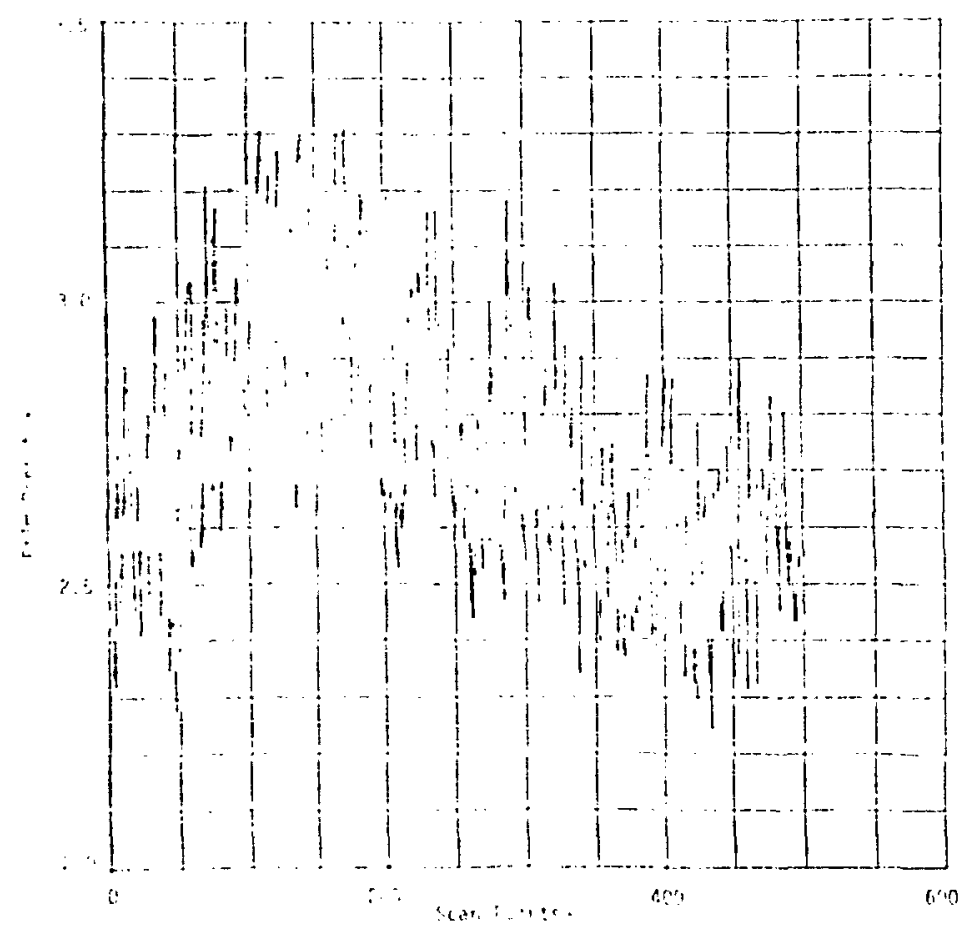

Fig. 3.2. A typical scan line of 500 data points.

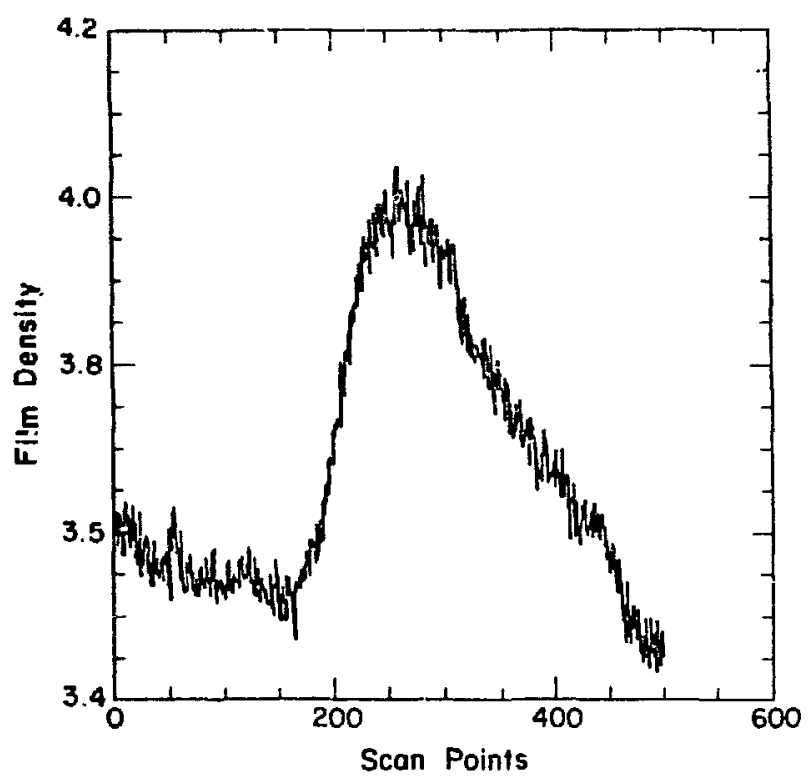

Fig. 3.3. Averaged data for Radiograph 2, Station 1.

\section{Least-Squares Solution}

The basic equation to be solved is

$$
\begin{aligned}
& g(x)=\int_{-R}^{R} h\left(x_{1}\right) f\left(x-x_{1}\right) d x, \\
& \text { where } h(x)=2 \sqrt{R^{2}-x^{2}}
\end{aligned}
$$

$f(x)=P_{1}$ $\left(0 \therefore x \leq P_{2}\right)$

$P_{3} \quad\left(P_{2}<x=P_{4}\right)$

$P_{3}+P_{5} x-P_{4} P_{5}-P_{6} x^{2}-P_{6} P_{4}^{2}\left(P_{4}<x\right)$.

The integral limits are as shown; for outside the range $-R$ to $+R, h\left(x_{1}\right)$ is zero.

The function $h\left(x_{1}\right)$ can overlap $f\left(x-x_{1}\right)$ in many ways. For instance, if $x \leq P_{2}-R$ then $h\left(x_{1}\right)$ overlaps $f\left(x-x_{1}\right)$ entirely to the left of $P_{2}$, and the integral of Eq. (3.3) reduces to

$$
g(x)=P_{1} \pi R^{2}
$$

However, if $P_{2}-R<x \leq P_{2}+R$

and $x \leq P_{4}-R$, 
FILE 1. LITEAR TMLL. E HIAE,

$10 / 25 / 74 \quad 17.42 .30$

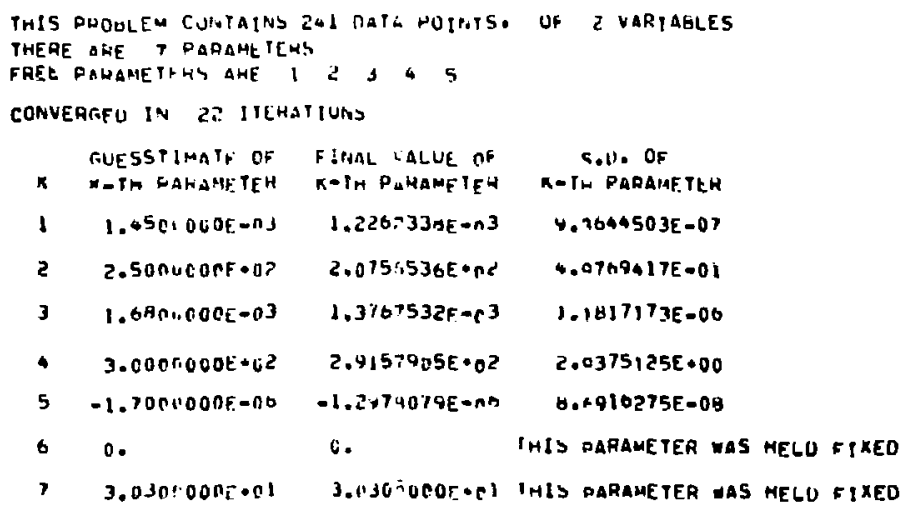

GQADTENT OF O-FUNCTION

SHOULD AE IE.RO

-1.36516 - $E-09$

$2.7238053 E-12$

$7.7830009 E-10$

$7.1684342 E-12$

$2.3937901 \vec{t}=08$

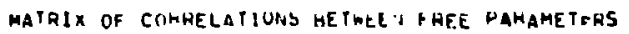

\begin{tabular}{|c|c|c|c|c|}
\hline $\begin{array}{r}1.000 \\
.300\end{array}$ & 1.309 & $\begin{array}{l}: 000 \\
: 473\end{array}$ & $\begin{array}{l}-.051 \\
-.273\end{array}$ & $\begin{array}{l}.02 \\
.120\end{array}$ \\
\hline .08 & .173 & $1=0(1, u)$ & $-.57 \mathrm{~g}$ & .27 \\
\hline-.0 & -.273 & $-.57 \theta$ & $2.00 \mathrm{r}$ & - - \\
\hline & .128 & $i^{7}{ }^{7}$ & -.887 & 1.00 \\
\hline
\end{tabular}

Fig. 3.4. Important output from least-squares routine.

then $h(x)$ overlaps the clamp and gap part of $f\left(x-x_{1}\right.$ : and Eq. (3.3) integrates to

$$
\begin{aligned}
g(x)= & \left(P_{3}-P_{1}\right) \\
& {\left[\left(x-P_{2}\right) \sqrt{R^{2}-\left(x-P_{2}\right)^{2}}+R^{2} \sin ^{-1}\left(\frac{x-P_{2}}{R}\right)\right] } \\
& +\left(P_{3}-P_{1}\right) \frac{\pi R^{2}}{2}
\end{aligned}
$$

So, as $x$ is varied, $h\left(x_{1}\right)$ overlaps $f\left(x-x_{1}\right)$ in different ways and each overlap leads to a unique form of Eq. (3.3). The six possible overlaps and the six equations that result are given in Appendix $A$.

The least-squares program needs partial derivatives of equation: like (3.6) and (3.7). Thus, purtials of all six equations for the various overlaps were derived. They are also given in Appendix $A$. As $x$ increases, or as $h(x)$ "t "aveis across" $f(x)$, the least-squares program determines the overiap and chooses the appropriate partial-derivative equations to use.

Appendix $B$ is a guide to the use of the leastsquares system. With it and an appropriate deck of cards cile can use the least-s ares routine under the KRONOS operating system.
An exarnsle of the most important pari of the output of the least-squares routine is given in Fig. 3.4.

\section{RESULTS}

A. Analytic Method and 1ts Application

Work with the model and the least-squares routine has been both frustrating and fascinating. A few results and observations are discussed below.

1. The initial value of $D=2 R=0.0297 \mathrm{~cm}$ in the point-spread function $h$ is too small to allow a reasonable fit of data on the left side of the gap. If $R$ is allowed to vary, the program finds it larger by a factor of 2 or 3 . This is understandable, for the true width of the point-spread function is the sum of the widths due to many effects; and the effects are such that one could justify almost any $D$ larger than $0.0297 \mathrm{~cm}$.

2. The values of $P_{2}$ and $P_{4}$ and the gap width are not critically depender.t on $R$.

3. The least-squares solution proceeds better with $R$ fixed because other parameters are closely correlated with $R$. We picked $R=303 \mu m$ for much of the work. 
8. The ledst-siguares proctrdis develops sinqularicies if $P_{2}$ or $P_{4}$ wander past the data bounds. Thus, ${ }_{2}$ and $P_{4}$ have been con:trained to stay within the data.

5. The least-squares prongam has aroolexy if $P_{2}$ gets bigger than $P_{4}$. Thus, $P_{2}$ has been consirained to be less than $P_{4}$.

5. The least-squares iteration process may develop huge and disastrous "corrections" in $P_{2}$ or $P_{4}$ without much notice. Thus. the change in $P_{2}$ or $P_{4}$ on any iteration is contined to be

$$
=500 \text {..m. }
$$

where $I$ is the iteration number.

7. Inciusion of too much data on the tail of the model leags the proqram to fit a "uriy" nonlinear tail on the richt side.

a. The ramnuting time required to do the fit is small. Typically. fits to 13 stations takes dbout a minuce of 7600 time.

The fits" to the data produced by the model look reasonably qood. An example is given in Fiq. 4-i. More examples are shown in Appendix $C$.

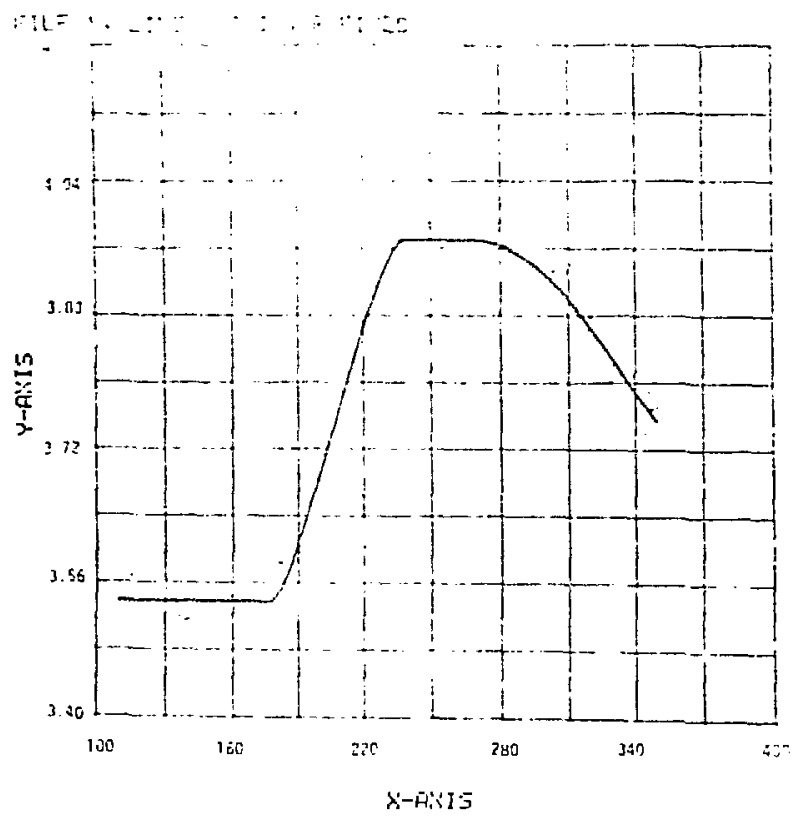

Fig. 4.1. Typical fit of model to data points.

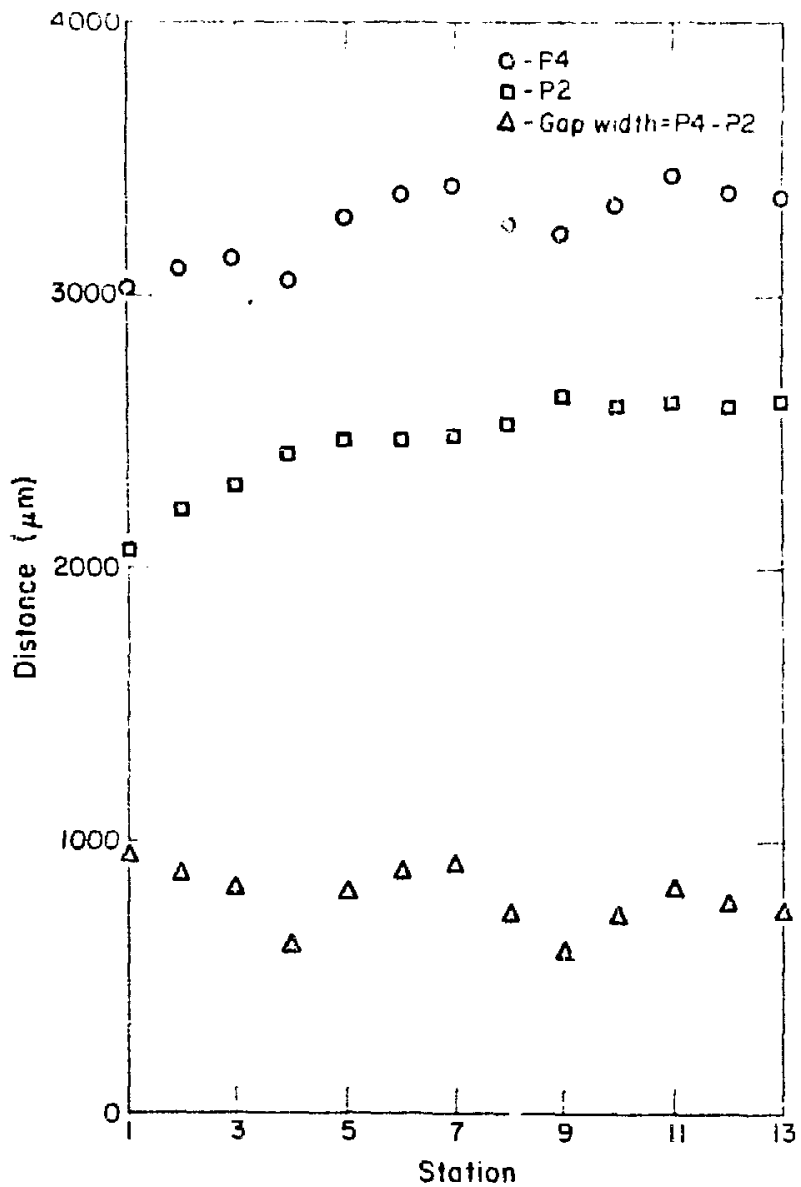

Fig. 4-2. Calculated gap eoges and gap width of Radiograph No. 2 (Runs IFR, IVG).

\section{B. Measurements}

Fig. 4-2 is a plot of the mieasured values of $P_{2}$ and $F_{4}$ for Stations 1 to 13 of Radiograph 2 . These two parameters define the edges of the gap. Their difference, the gap width. is also shown in Fig. 4-2. Figure 4-3 shows similar results for Stations 14 to 26 of Radiograph 2. Figure 4-4 presents a plot of the sums of the gaps found in Radiograph 2. Figures 4-5 through 4-7 show results for Radiograph 5 like those shown in Figs. 4-2 chrough 4-4 for Radiograph 2.

A few general comnents are in order before proceeding to a detailed examination of the results shown in Figs. 4-2 through 4-7. First, the sets of

* 11 measurements discussed here are those made on the original radiograph, expressed in $\mu \mathrm{m}$. 
points representing the gap edges $P_{2}$ and $P_{4}$ jenerally have a sloue due to the fact that the scan lines were not precisely perpendicular to the gap. Second, most $P_{2}$ and $P_{4}$ point sets are reasonably smooth, as expected, with gradual changes that might well be caused by bending; but occasional outlying points away from a smooth course are seen. These could be due to obfuscation of the gap at that point by other physical parts imaged in the radiograph. Third, it was hypothesized that the gap widths not only would vary smoothly but that, for any one radiograph, the sumis of the gaps would be a constant of the order of $1500 ;$;ाm.

Figures 4-2 and 4-5 show particularly good definition of the sharp edge $P_{2}$ on the nonparallax (right) gap of the radiographs. The $\mathrm{P}_{2}$ edges on the left gaps of the radiographs, where the parallax is severe, are also well defined. The $P_{4}$ edges of the gaps, as found by the least-squares routine, show more variance; but if allowance is made for exclusion of some outlying points, even these edges can be fit by smooth curves. $P_{4}$ in Radiograph 5 is a possible exception. It shows considerably more scatter than the other $\mathrm{P}_{4}$ edges.

Smooth curves drawn through the $P_{2}, P_{4}$ measurements lead one to believe that there was indeed some bending of the physical pieces in the fuel element assembly. For example, $P_{2}$ of Fig. 4-2 indicates that that "edge" is bent, for it slopes off sharply and uniformly to the left. A similar bend can be visualized in $P_{4}$ of Fig. 4-3. In contrast, $P_{2}$ of Fig. 4-6 would appear to show a number of gradual deformations. The extent to which these data reflect real changes is not known and probably will not be known; for a disassembly for investigative purposes presumably would inofuce additional changes. It is the author's feeling that smooth curves drawn through the best of the data do represent the "edges" of the gap quite well, and that deviations from a straight line do reflect physical changes.

As noted previously, it was thought that the sum of left and right gap widths taken along a line perpendicular to the length of the gaps would be a constant. This "constant" was $0.14224(1 \pm 0.1) \mathrm{cm}$, which, taking $9 \%$ enlargement into account, converts to $1550(1 \pm 0.1) \mu m$. The sums of the gaps, the
1550 m line, and lines representing a $\pm 10 \%$ change from $1550 \mu \mathrm{m}$ are shown in Figs. 4-4 and 4-7. The gap sums for Radiograph 2 tend to fall substantially above the anticipated sum, while those for Radiograph 5 fall fairly well within the bounds anticipated despite the fact that $P_{4}$ in Fig. $4-6$ is quite "noisy." The author does not know why the gap sums for Radiograph 2 are so great, but it would appear that at least some of the contribution comes from a leveling-out of $\mathrm{P}_{4}$ as one goes from left to right in Fig. 4-3. The $P_{4}$ data fit a smooth curve rather well, and the author has no particular reason to doubt that this edge does curve up toward the right side.

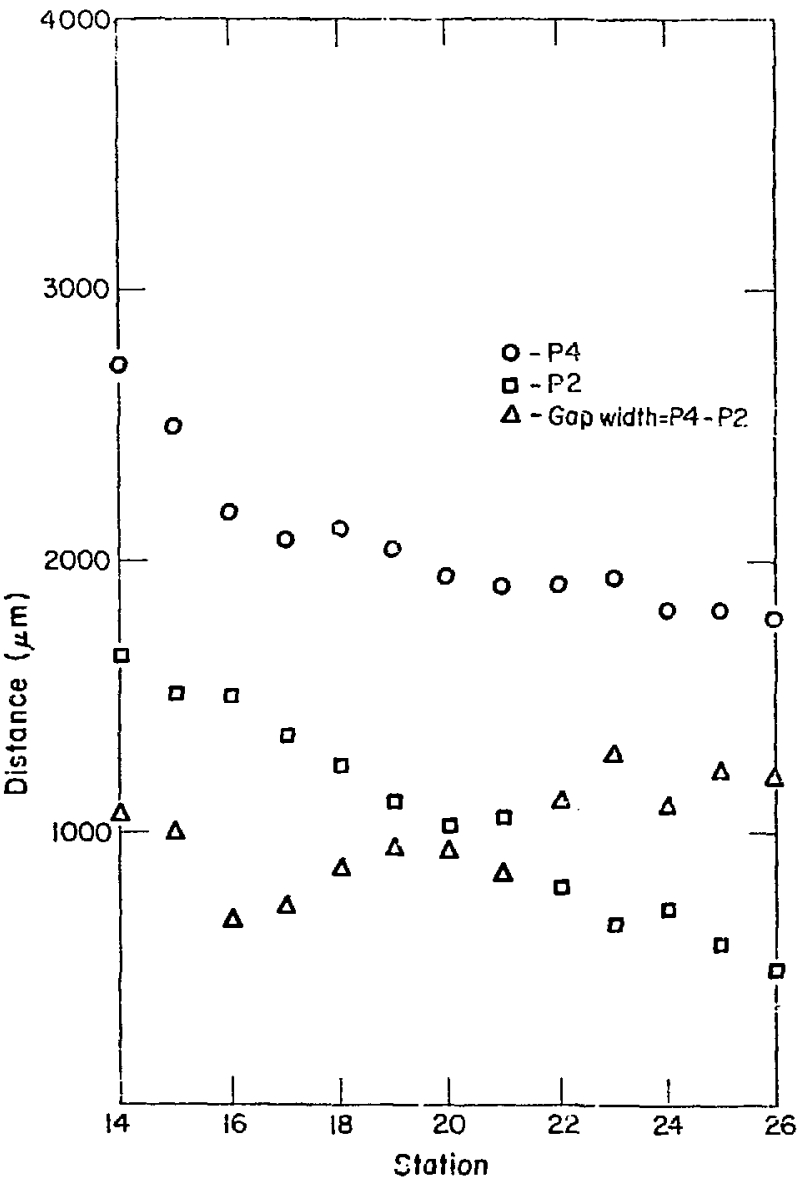

Fig. 4-3. Calculated gap edges and gap width of Radiograph No. 2 (Runs 1VK, 1PH). 

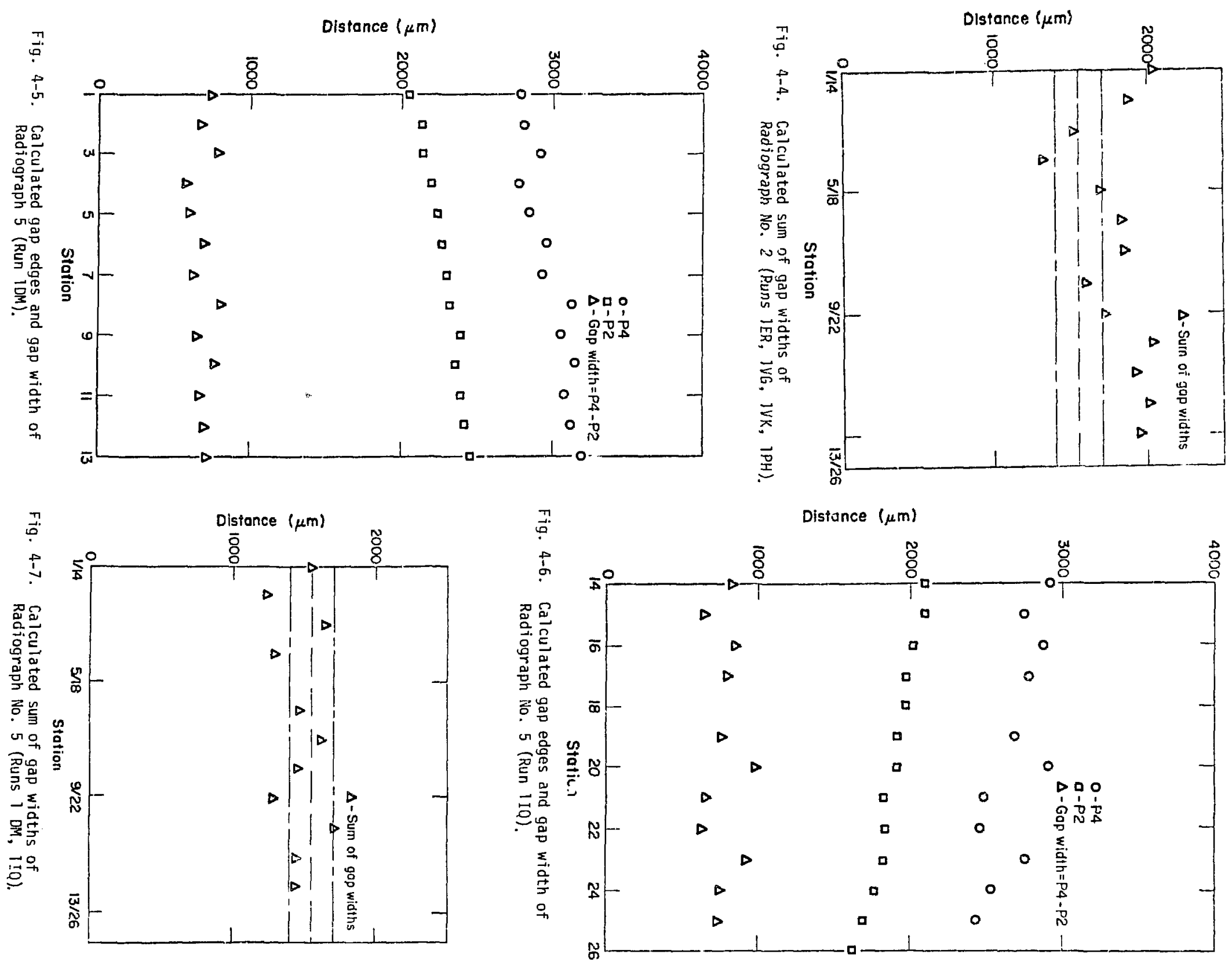
v. CONCLUSIONS

A. Analytical Methods

The idea of using a model of the gap and applying a least-squares fit to determine the parameters of the model has worked well. The methods developed were easy to use, required little computer time, and were remarkably insensitive to noise and other degradations.

B. Fuel Bundle Gaps

The fuel bundle gap edges found in this study show bending of various kinds. The statistical parameter; zssociated with the fits to data at various stations indicate that the fits are indeed good, that the results are reliable, and that the smooth bendiny of the gap edges, as observed, is actually present.

\section{FUTURE WORK}

The investigation reported here has suggested a variety of paths for future work. For instance, the computer runs took little time but were done in a batch mode. If the runs could be done in an interactive mode, it would be possible to optimize the choice of data bounds, model (1 inear or nonlinear tail), free parameters, convergence criteria, etc. with such optimization, the results might improve considerably. Better results might also be obtained with a point-spread function that had a different shape; ${ }^{*}$ and an improved understanding of the effects of parallax on the left side might well produce better results there.

* Results were relatively insensitive to point-spread function width, but the effect of PSF shape is unknown.
The general approach of fitting a model of few parameters to low quality images is an interesting area for future research. It is, in essence, the epitome of parameter reduction in which only a few "answers" are desired fron a wealth of data. It has the potential of being applied to any case in which an object of "known" geometry is imaged but in which the orientation, size, etc., are not known. For such cases, the model/point-spread function/ least-squares fit methods used here offer a great dea?; and research in the area would be worthwhile.

\section{ACKNOWLEDGMENTS}

The author extends his thanks to all who helped with this work, and in particular to Paul Gnadt and Allen Vanhull of Holifield National Laboratory for initiating and sponsoring the work, and for their interest, patience, and cooperation in seeing it through; Richard Beckman of LASL Group $\mathrm{C}-5$, who helped with the initial setup of the problem and with the use of the least-squares routine; Thomas McWilliams of LASL. Group C-5, who set up and debugged the first fitting program; Carlotta McInteer of LASL Group $\mathrm{C}-5$, who aided in running and modifying the least-squares routine; Richard Bagley and Rosemary $0^{\prime}$ Connor for their efforts in scanning the radiographs, digitizing the data, and averaging it to give data sets suitable for the least-squares program; and D. H. Janney and B. R. Hunt of LASL Group $\mathrm{C}-8$ who provided encouragement, good suggestions, and administrative patience and support. 


\section{APPENDIX A}

SIX CASES OF OVERLAP

The material shown below illustrates the six possible ways in which $h(x)$ and $f(x)$ can overlap. The results obtained on integrating

$$
g(x)=\int_{-R}^{R} h\left(x_{1}\right) f\left(x-x_{1}\right) d x_{1}
$$

in each case are also given.

The partial differentials of the equations for each case are needed for use in the least-squares program. These differentials are shown in the last part of this appendix.

1. Six Possible Overlaps

Case I: $x \leq P_{2}-R$

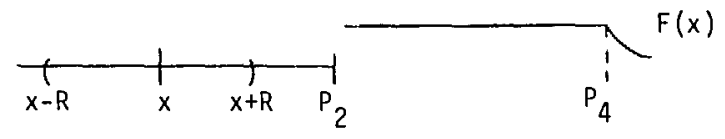

Case II: $\quad P_{2}-R<x \leq P_{2}+R$ and $x \leq P_{4}-R$

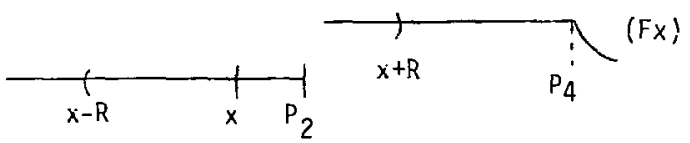

Case III: $P_{2}+R<x \leq P_{4}-R$



Case IV: $P_{4}-R<x \leq P_{4}+R$ and $x>P_{2}+R$
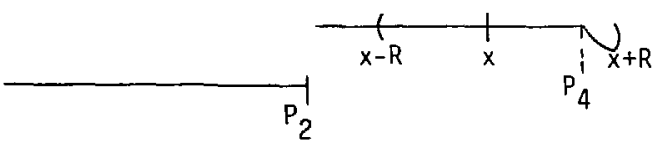

Case $V: \quad x>P_{4}+R$

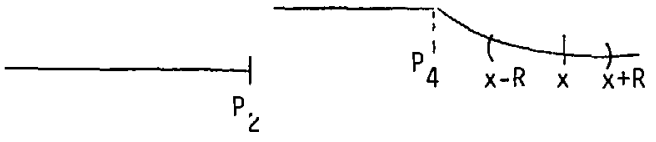

Case VI: $x \leq P_{2}+R$ and $x \geq P_{4}+R$



2. Equations Resulting from Integration in the Six Overlap Câses

Case 1: $x \leq P_{2}-R$

$g(x)=P_{1} R^{2} \pi$

Case II: $P_{2}-R<x \leq P_{2}+R$ and $x \leq P_{4}-R$

$g(x)=\left(P_{3}-P_{1}\right)\left[\left(x-P_{2}\right) \sqrt{R^{2}-\left(x-P_{2}\right)^{2}}+R^{2} \sin ^{-1}\left(\frac{x-P_{2}}{R}\right)\right]$

$$
+\left(P_{3}+P_{1}\right) \frac{R^{2} \pi}{2}
$$

Case III: $\quad P_{2}+R<x \leq P_{4}-R$

$$
g(x)=P_{3} R^{2 \pi}
$$

Case IV: $P_{4}-R<x \leq P_{4}+R$ and $x>P_{2}+R$

$$
\begin{aligned}
& g(x)=\left[2 P_{3}+P_{5}\left(x-P_{4}\right)+P_{6}\left(x^{2}-P_{4}^{2}\right)+\frac{P_{6} R^{2}}{4}-\right] \frac{R^{2} \pi}{2} \\
& +\left[P_{5}\left(x-P_{4}\right)+P_{6}\left(x^{2}-P_{4}^{2}\right)+\frac{P_{6} R^{2}}{4}-\right]\left(x-P_{C}\right) \sqrt{R^{2}-\left(x-P_{4}\right)^{2}}
\end{aligned}
$$

$+\left[\frac{2}{3} P_{5}+\frac{4}{3} P_{6} x-\frac{1}{2} P_{6}\left(x-P_{4}\right)\right]\left[R^{2}-\left(x-P_{4}\right)^{2}\right]^{3 / 2}$

$+\left[P_{5}\left(x-P_{4}\right)+P_{6}\left(x^{2}-P_{4}^{2}\right)+\frac{P_{6} R^{2}}{4}\right] R^{2} \sin ^{-1}\left(\frac{x-P_{4}}{R}\right)$

Case $V: \quad x>P_{4}+R$

$g(x)=\left[P_{3}+P_{5}\left(x-P_{4}\right)+P_{6}\left(x^{2}-P_{4}^{2}\right)+\frac{P_{6} R^{2}}{4}\right] R^{2} \pi$

Case VI: $x \leq P_{2}+R$ and $x \geq P_{4}-R$

$$
\begin{aligned}
g(x) & =\frac{R^{2} \pi}{2}\left[P_{1}+P_{3}+P_{5}\left(x-P_{4}\right)+P_{6}\left(x^{2}-P_{4}{ }^{2}\right)+\frac{1}{4} P_{6} R^{2}\right] \\
& +\left(P_{3}-P_{1}\right)\left[\left(x-P_{2}\right) \sqrt{R^{2}-\left(x-P_{2}\right)^{2}}+R^{2} \sin ^{-1}\left(\frac{x-P_{2}}{R}\right)\right]
\end{aligned}
$$


$+\left(x-P_{4}\right) \sqrt{R^{2}-\left(x-P_{4}\right)^{2}}\left[P_{5}\left(x-P_{4}\right)+P_{6}\left(x^{2}-P_{4}^{2}\right)+\frac{1}{4} P_{6} R^{2}\right]$

$+R^{2} \sin ^{-1}\left(\frac{x-P_{4}}{R}\right)\left[P_{5}\left(x-P_{4}\right)+P_{6}\left(x^{2}-P_{4}{ }^{2}\right)+\frac{1}{4} P_{6} R^{2}\right]$

$+\left[R^{2}-\left(x-P_{4}\right)^{2}\right]^{3 / 2}\left[\frac{2}{3} P_{5}+\frac{4}{3} P_{6} x \cdot \frac{1}{2} P_{6}\left(x-P_{4}\right)\right]$

3. Partials Needed by Least-Squares Program

Case I: $x \leq P_{2}-R$

$$
\frac{\partial g}{\partial P_{1}}=R_{T}^{2}
$$

Case II: $\quad P_{2}-R<x \leq P_{2}+R$

$\frac{3 g}{\partial P_{1}}=-\left[\left(x-P_{2}\right) \sqrt{R^{2}-\left(x-P_{2}\right)^{2}}+R^{2} \sin ^{-1}\left(\frac{x-P_{2}}{R}\right)\right]+\frac{R^{2}}{2}$

$$
\frac{\partial g}{\partial P_{2}}=-2\left(P_{3}-P_{7}\right) \sqrt{R^{2}-\left(x-P_{2}\right)^{2}}
$$

Case III: $P_{2}+R<x \leq P_{4}-R$

$$
\frac{\partial g}{\partial P_{3}}=R^{2} \pi
$$

Case IV: $P_{4}-R<x \leq P_{4}+R$ and $x>P_{2}+R$

$$
\begin{aligned}
& \frac{\partial g}{\partial P_{3}}=R^{2} \pi \\
& \frac{\partial g}{\partial P_{4}}=\left[-P_{5}-2 P_{4} P_{6}\right] R^{2} \sin ^{-1}\left(\frac{x-P_{4}}{R}\right) \\
& \frac{\partial g}{\partial P_{5}}=\frac{R^{2} \pi}{2}\left[x-P_{4}\right]+\frac{2}{3}\left[R^{2}-\left(x-P_{4}\right)^{2}\right]^{3 / 2}
\end{aligned}
$$

$+\left(x-P_{4}\right)^{2} \sqrt{R^{2}-\left(x-P_{4}\right)^{2}}+R^{2}\left(x-P_{4}\right) \leqslant \operatorname{in}^{-1}\left(\frac{x-P_{4}}{R}\right)$

$\frac{3 g}{\partial P_{j}}=\frac{R^{2} \pi}{2}\left[x^{2}-P_{4}^{2}\right]+\left[\frac{4}{3} x-\frac{1}{2}\left(x-P_{4}\right)\right]\left[R^{2}-\left(x-P_{4}\right)\right]^{3 / 2}$

$+\left[x^{2}-P_{4}^{2}+\frac{1}{4} R^{2}\right]\left(x-P_{4}\right) \sqrt{R^{2}-\left(x-P_{4}\right)^{2}}$

$+\left[x^{2}-P_{4}^{2}+\frac{1}{4} R^{2}\right] R^{2} \sin ^{-1}\left(\frac{x-F_{4}}{R}\right)+\frac{R^{4} \pi}{8}$

$\frac{7 g}{\partial R}=R-\left[2 P_{3}+P_{5}\left(x-P_{4}\right)+P_{6}\left(x^{2}-P_{4}{ }^{2}\right)+\frac{1}{2} P_{6} R^{2}\right]$ $+\left[2 P_{5}+4 P_{6} x-\frac{3}{2} P_{6}\left(x-P_{4}\right)+\frac{1}{2} P_{6}\left(x-P_{4}\right)\right] R \sqrt{R^{2}-\left(x-P_{4}\right)}$.

$+\left[2 P_{5}\left(x-P_{4}\right)+2 P_{6}\left(x^{2}-P_{4}^{2}\right)+P_{6} R^{2}\right] R \sin ^{-1} \frac{x-P_{4}}{R}$

Case $V: P_{4}+R<x$

$$
\frac{\partial g}{\partial P_{3}}=n^{2} n
$$$$
\frac{\partial g}{\partial P_{4}}=R^{2} \pi\left[-P_{5}-2 P_{4} P_{6}\right]
$$$$
\frac{\partial g}{\partial P_{5}}=R^{2} \pi\left[X-P_{4}\right]
$$

$$
\frac{\partial g}{\partial P_{6}}=R^{2} \pi\left[x^{2}-P_{4}^{2}\right]+\frac{R^{4}}{4}
$$

$\frac{\partial g}{\partial R}=\left(P_{3}+P_{5}\left(x-P_{4}\right)+P_{6}\left(x^{2}-P_{4}^{2}\right)\right) 2 R \pi+R^{3} \pi P_{6}$

Case VI: $x-R \leq P_{2}$ and $x+R \geq P_{4}$

$\frac{\partial g}{\partial P_{i}}=\frac{R^{2} \pi}{2}-\left(x-P_{2}\right) \sqrt{R^{2}-\left(x-P_{2}\right)^{2}}-R^{2} \sin ^{-1}\left(\frac{x-P_{2}}{R}\right)$

$$
\frac{\partial g}{\partial P_{2}}=-2\left(P_{3}-P_{1}\right) \sqrt{R^{2}-\left(x-P_{2}\right)^{2}}
$$

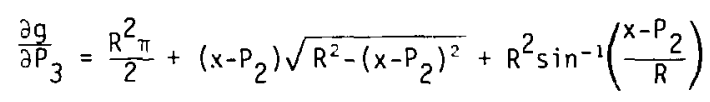

$\frac{\partial g}{\partial x_{4}}=\frac{R^{2} \pi}{2}\left[-P_{5}-2 P_{4} P_{6}\right]$
$-2 \sqrt{R^{2}-\left(x-P_{4}\right)^{2}}\left[P_{5}\left(x-P_{4}\right)+P_{6}\left(x^{2}-P_{4}^{2}\right)+\frac{1}{4} P_{6} R^{2}\right]$
$+\left(x-P_{4}\right) \sqrt{R^{2}-\left(x-P_{4}\right)^{2}}\left[P_{5}+4 P_{6}-P_{4} P_{6} x-\frac{3}{2} P_{6}\left(x-P_{4}\right)\right]$

$+R^{2} \sin ^{-1}\left(\frac{x-P_{4}}{R}\right)\left[-P_{5}-2 P_{4} P_{6}\right]+\frac{1}{2} P_{6}\left[R^{2}-\left(x-P_{4}\right)^{2}\right]^{3 / 2}$

$\frac{\partial g}{\partial P_{5}}=\frac{R^{2} \pi}{2}\left[x-P_{4}\right]+\left(x-P_{4}\right)^{2} \sqrt{R^{2}-\left(x-P_{4}\right)^{2}}$

$+R^{2}\left(x-P_{4}\right) \sin ^{-1}\left(\frac{x-P_{4}}{R}\right)+\frac{2}{3}\left[R^{2}-\left(x-P_{4}\right)^{2}\right]^{3 / 2}$

$$
\frac{\partial g}{\partial P_{6}}=\frac{R^{2} \pi}{2}\left[x^{2}-P_{4}^{2}+\frac{1}{4} R^{2}\right]
$$

$+\left(x-P_{4}\right)\left(x^{2}-P_{4}^{2}+\frac{1}{4} R^{2}\right) \sqrt{R^{2}-\left(x-P_{4}\right)^{2}}$ 


$$
\begin{array}{lc}
+R^{2} \sin ^{-1}\left(\frac{x-P_{4}}{R}\right)\left(x^{2}-P_{4}^{2}+\frac{1}{4} R^{2}\right) & +2 R\left(P_{3}-P_{1}\right) \sin ^{-1}\left(\frac{x-P_{2}}{R}\right) \\
+\left[R^{2}-\left(x-P_{4}\right)^{2}\right]^{3 / 2}\left[\frac{4}{3 x}-\frac{1}{2}\left(x-P_{4}\right)\right] & +\sqrt{R^{2}-\left(x-P_{4}\right)^{2}}\left[-P_{6} R\left(x-P_{4}\right)+2 R P_{5}+4 R P_{6} x\right] \\
\frac{\partial g}{\partial R}=R_{\pi}\left[P_{1}+P_{3}+P_{5}\left(x-P_{4}\right)+P_{6}\left(x^{2}-P_{4}{ }^{2}\right)+\frac{1}{2} P_{6} R^{2}\right] & +\sin ^{-1}\left(\frac{x-P_{4}}{R}\right) R\left[2 P_{5}\left(x-P_{4}\right)+2 P_{6}\left(x^{2}-P_{4}{ }^{2}\right)+P_{6} R^{2}\right]
\end{array}
$$

APRENDIX 8

GUIDE TO THE BATCH USE OF LEAST-SQUARES PROGRAM

\section{BACKGROUND}

LSMFT is a collection of programs combined into a system to permit a general approach to leastsquares problems. Written for the $\operatorname{CDC} 6600$ and 7600 computers, LSMFT is designed to accept freeformat input of problem specification and data, choice of prewritten or user-specified functions, choice of optimizing algorithm, and selected output with various graphical displays.

LSMFT has been designed so that it probably will never be declared "finished." That is, as new minimizing algorithms are developed, as new display methodology appears, and as interactive computing grows at LASL, LSMFT can be expected to form the basis of adapting these new features to the matter of least-squares analysis.

\section{SOME MATHEMATICAL FORMULATIONS}

Consider a collection of $N$ points, each point having $M$ elements. Let $x_{n}=\left(x_{n 1}, x_{n 2}, \ldots, x_{n M}\right)$ denote the nth such point. Then the entire collection can be represented by an NXM matrix, $x=\left(x_{n m}\right)$, $n=1,2, \ldots, N$ and $m=1,2, \ldots, M$.

Consider next a function of $M$ variables and $P$ parameters, say $f_{n}\left(z_{1}, z_{2}, \ldots, z_{M} ; n_{1}, n_{2}, \ldots, n_{p}\right)$ $=0$. If $f_{n}(z ; 9)=0$ is chosen properly and the vector $x_{n}$ is "perfect," it is reasonable that $f_{n}\left(x_{n} ; \cdot-i\right)$ $=0$ be satisfied for all $N$ functions and vectors $x_{n}$.

In the absence of "perfection" of the data and the functions and knowledge of the values of the elements of the parameter vector., consider the problem of finding a vector, say such that ${ }^{\star}$ is, in some sense, "best" for the choice of the $N$ functions and the given matrix of data.

LSMFT is designed to find $a^{\star}$ by the method of least squares. That is, e* is the choice of : such that the quadratic form

$$
S()=\sum_{n=1}^{N} \sum_{n^{\prime}=1}^{N} f_{n}\left(x_{n} ; 9\right) w_{n m}, f_{n^{\prime}}\left(x_{n^{\prime}} ; \theta\right)
$$

is smaller when $\theta=\hat{e}^{*}$ than for any other choice of A. The scalars $w_{n m}$ ' are elements of a "weight matrix," say $w=\left(w_{n m^{\prime}}\right), n, n^{\prime}=1,2, \ldots, N$.

If $F(X ; \theta)$ is an $N$-element vector whose $n$th element is $f_{n}\left(x_{n} ; \theta\right)$ and $F^{\prime}(x ; \theta)$ denotes its transpose, then $S(\theta)$ can be written

$$
S(\theta)=F^{\prime}(X ; \theta) W F(X ; \theta) \text {. }
$$

When $W$ is a diagonal matrix and $F(X ; i)$ is linear in the elements of $\theta$, the solution is found by solving the $P$ linear "normal equations" which are obtained by differentiating $S(0)$ with respect to each of the elements of $\mathrm{B}$. Some arbitrariness is involved, of course, should the number of parameters be larger than the number of functions or should the nomal equations be singular or should $W$ be singular, but various conventions exist for resolvirg these difficulties.

When, however, any one $f_{n}\left(x_{n} ; "\right)$ is nonl inear in at least one of the parameters. the nomial eauations are nonlinear and special algoritluns must be employed. These inay range from simple searches of 
the P-dimensional parameter space to sophisticated mathematically-based procedures.

\section{HI. SOME ILLUSTRATIVE EXAMPLES}

Most problems will not employ the bajic LSMFT least-squares formulation outlined in Section II. The following examples are intended to illustrate how some of the more conventional least-squares problems may be stated in terms of LSMFT conventions.

Example 1: The straight line. Suppose $N$

pairs of observed data are available, denoted $\left(x_{n}, y_{n}\right), n=1,2, \ldots, N$. Let $f_{n}\left(z_{1}, z_{2} ; \theta_{1},:_{2}\right)=$ $y_{n}-a_{1}-y_{2} x_{n}=0$ be the function of interest. Let the weight matrix $W$ be the identity matrix. Then the function to be minimized can be written

$$
S(\theta)=\sum_{n=1}^{N}\left(y_{n}-\theta_{1}-3_{2} x_{n}\right)^{2},
$$

exactly the sum of squares found in most first encounters with least squares. In this formulation $y$ often is called the dependent variable and $x$ is the independent variable, while $\partial_{1}$ is the intercept and $\bar{S}_{2}$ is the slope of the line. Once $9^{*}$ is found by solving the $2 \times 2$ linear system of normal equations, $\because{ }_{1}$ and $\theta^{\star}{ }_{2}$ are the estimated slope and intercept obtained by using the particular set of $N$ pairs of data at hand.

For LSMFT the matrix $y$ has $\mathrm{N}$ rows and $2 \mathrm{col}-$ umns. One column is designated the dependent variatle, the other is designated the independent variable. Uniess otherwise specified by the user, LSMFT is designed to use the first column of $X$ as the dependent variable. Thus, the sum of squares can be written

$$
S(s)=\sum_{n=1}^{N}\left(x_{n 1}-a_{1}-5_{2} x_{n 2}\right)^{2} .
$$

Example 2: General linear hypothesis model of full rank. The function to be fitted is linear in all $P$ parameters. A matrix $Z$ is set up by zur; menting a vector of l's with the matrix $X$, where $X$ has dimensions $N$ and $M=(P-I)$. Again assuming that $W$ is the identity matrix, the function to be minimized is

$$
S(\because)=(Y-Z) \cdot(Y-Z i)
$$

where $Y$ is an $\mathrm{N}$-element vector of observations of the dependent variable. The minimizing value of $u$ is given by

$$
A^{*}=\left(Z^{\prime} Z\right)^{-1} Z^{\prime} Y .
$$

In LSMFT terminology, $f_{n}\left(x_{n} ; \theta\right)=x_{n 1}-\theta_{1}-$ $\theta_{2} x_{n 2}-\theta_{3} x_{n 3}-\ldots-\theta_{p} x_{n}(P-1)=0$ is the function of interest for $n=1,2, \ldots, N$. Only the matrix $x$ need be stored, since the first column of l's is taken care of in the formulation of the function,

Example 3: Multiple regimes. The notation $f_{n}\left(x_{n} ; 9\right)$ may seem redundant for most ieast-squares problems, because the model usually is the same for sach vector $x_{n}$. However, some problems require the more general notation.

Consider $N=n_{1}+n_{2}$ observations. For $1 \geq n \geq n_{1}$, the function of interest is $f_{n}\left(x_{n} ; \theta\right)=$ $x_{n 1}-\theta_{1}-\theta_{2} x_{n 2}=0$, and for $n_{1}+1 \leq n \leq N$, the function is $f_{n}\left(x_{n} ; \theta\right)=x_{n 1}-\theta_{3}-\theta_{2} x_{n 2}=0$. These represent two parallel lines. If each were fitted alone, the equality of the slopes could not be assured.

More complicated mulciple regime problems can be treated with LSMFT. It is not necessary that the data and functions match sequentially, as in the parallel line example. Sometimes the choice of function for a particular $x_{n}$ can be made by an indicator variable in one column of the data matrix $x$.

\section{USE OF LSMFT}

LSMFT is available as a CROS $^{\star}$ cafeteria batch job using Class 2 resident fileset and on KRONOS either in batch mode or through a remote keyboard terminal. In either case, a preprocessor sets minimum array sizes needed to run and sets calls to subroutines and library functions. The main program CCPROC calls PACKALG to fit the data to the selected function, calls OUTPACK to print answers, then calls PLTPACK if requested.

Users of the old PACKAGE routines will find the preprocessor solves the problem of exceeding code dimension sizes, but the new code will not count data points. A subroutine can be written to do this, however, if you set the number of points to a reasonable upper limit for the preprocessor to use ${ }^{\star}$ CROS is a LASL 7600 operating system. 
and then reset the number of points to the exact value in the subroutine. It is possible to add a dummy variable by reading it in as an extra independent variable, then resetting the number of variables appropriately. The new code does not calculate the variance of the predicted mean.

\section{APPENDIX C}

This Appendix contains (1) various parts of run IVG, including all of the printing associated with Station 1, Radiograph 2, and (2) all the fits for Stations 1 through 13, Radiograph 2.

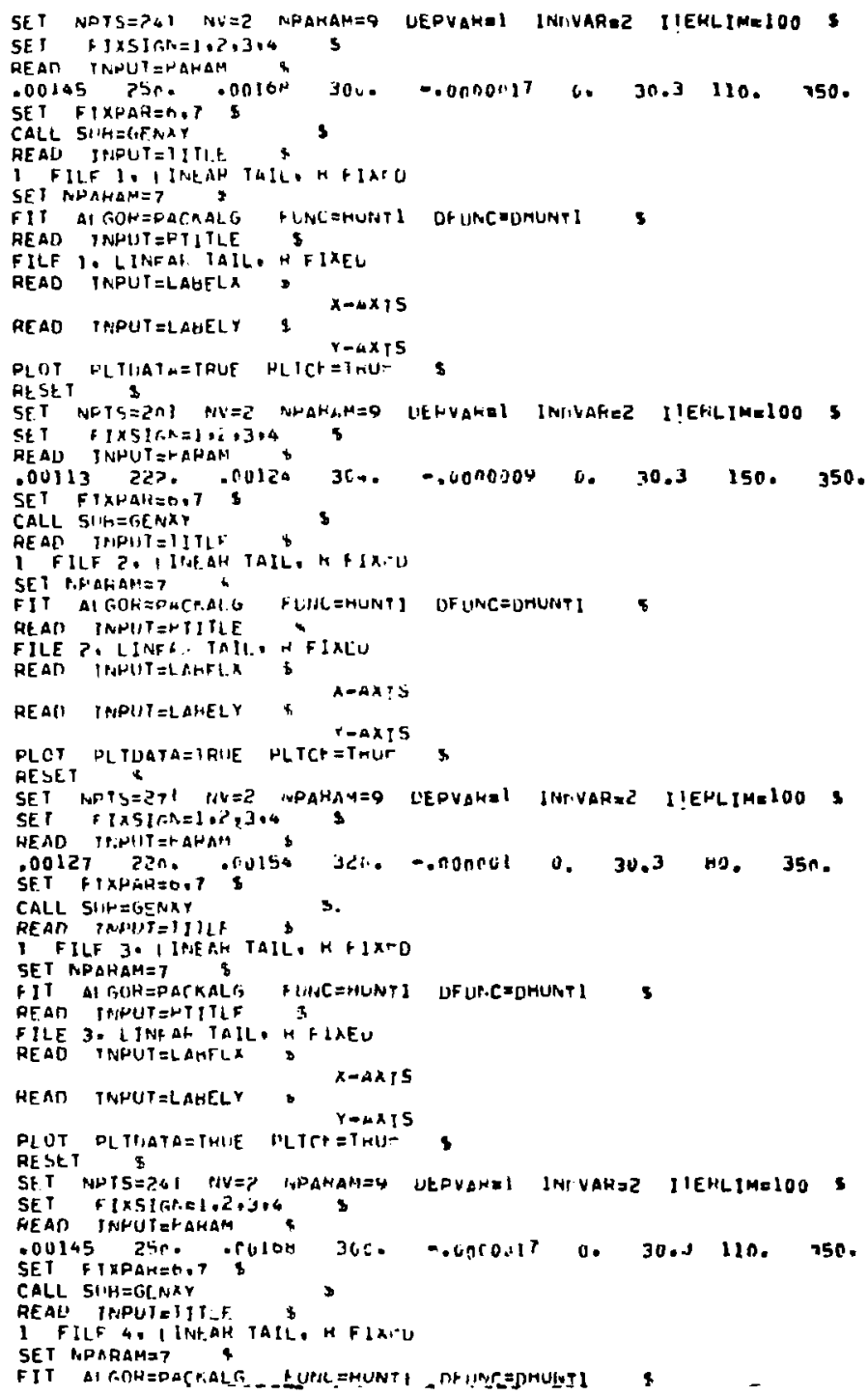




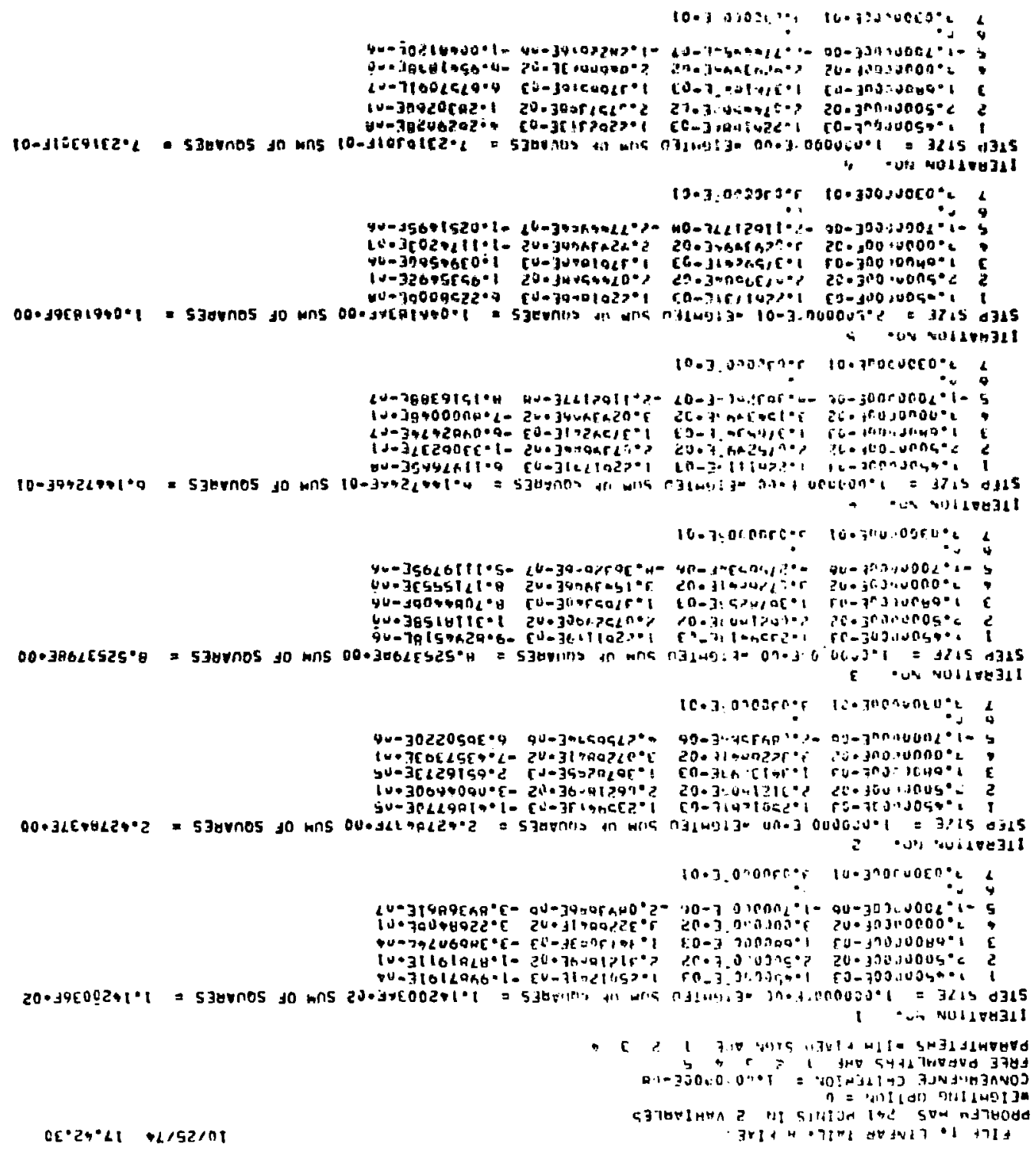

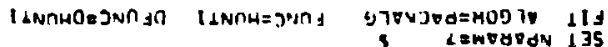

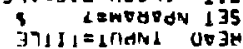



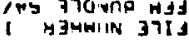

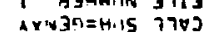

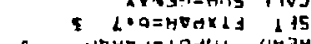






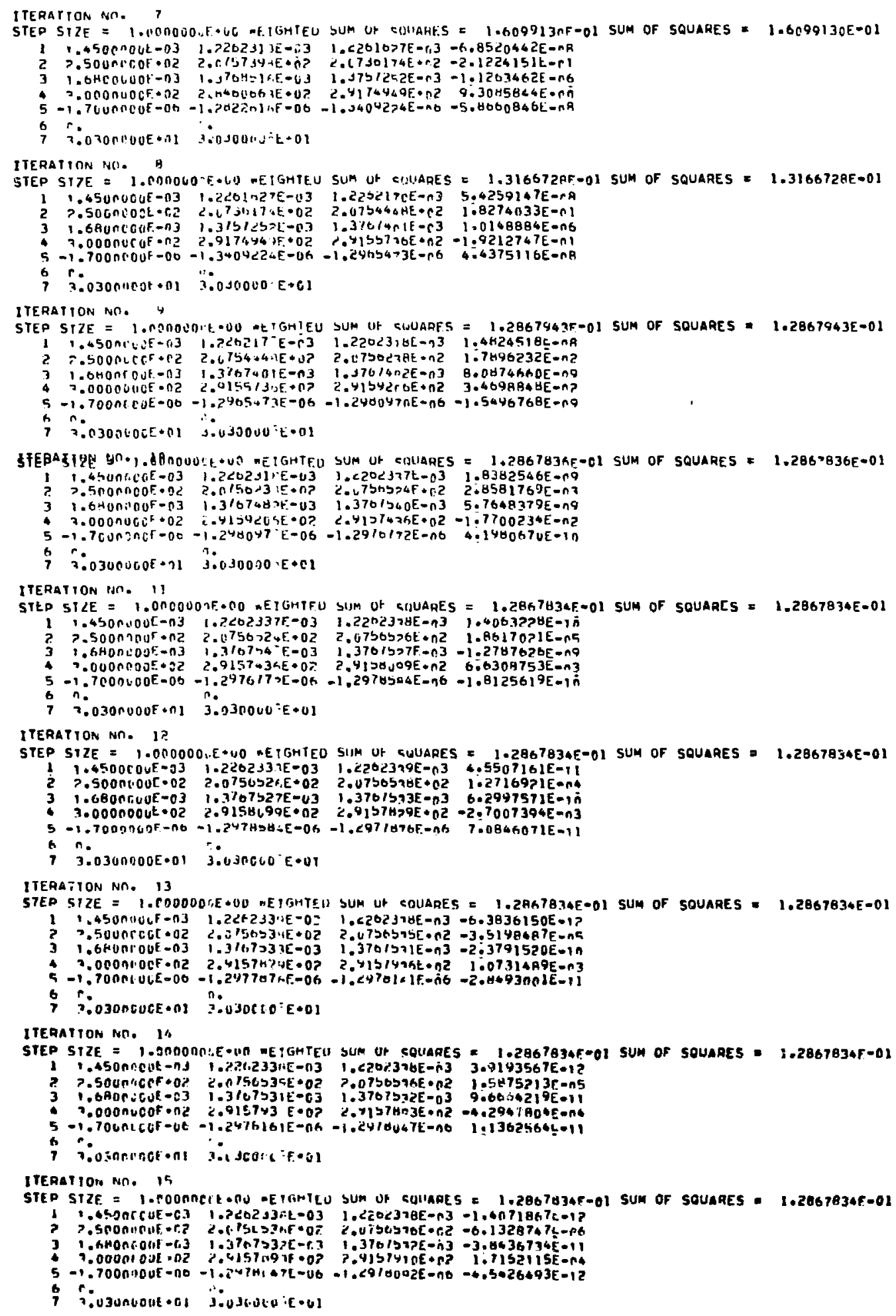




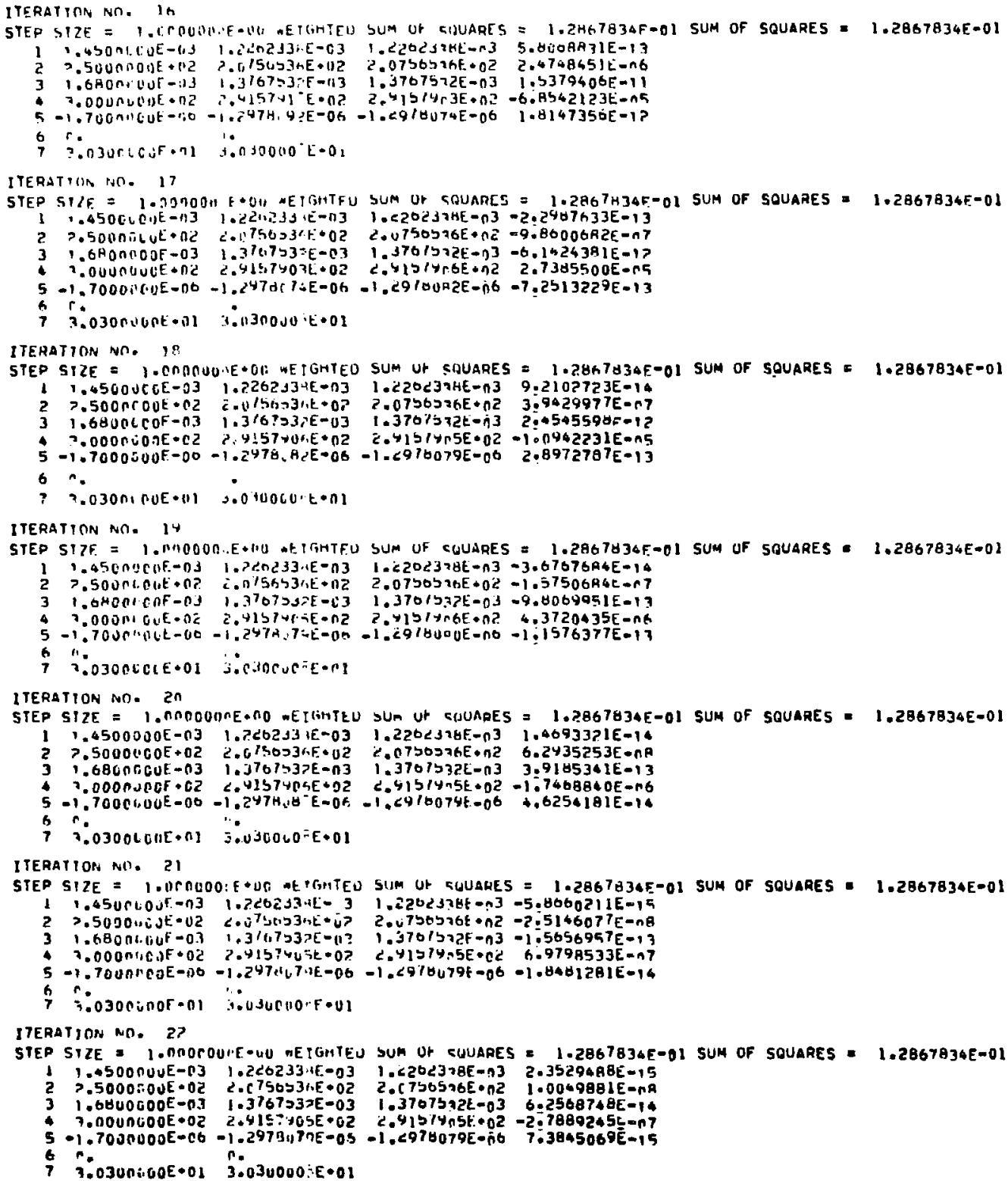

FILE I. LINEAR TAIL. H FIXES $10 / 25 / 74 \quad 17.42,30$

TMIS PDOHLEM CUNTAINS 241 DATA MOINTS, OF 2 VARIAGLES THERE GRE 7 PARAHETCKS

FAE PAHANETFHS AHE 12345

COHVERGEO IH 22 ITEHATIUNS

\begin{tabular}{|c|c|c|c|}
\hline $\mathbf{K}$ & $\begin{array}{l}\text { FUESSTIMATE: OF } \\
\text { X-TH PAPAHE TEH }\end{array}$ & $\begin{array}{l}\text { Flmal value of } \\
\text { R-IM PHAMETER }\end{array}$ & $\begin{array}{c}\text { S.D. OF } \\
\text { K-TH PARAMETER }\end{array}$ \\
\hline 1 & 1.450 COOOE-0J & $1,2267330 E-n 3$ & $4.3644 .23 E=07$ \\
\hline 2 & $2.500400 \mu f .02$ & $2.0756536 E \cdot 02$ & $0.0769617 E-01$ \\
\hline 3 & $1.6 A_{00000 E-03}$ & $1.3767532 E-c^{3}$ & $1,1817,736-06$ \\
\hline 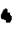 & $3.0000000 E \cdot 02$ & $2.9157905 \varepsilon \cdot 02$ & $2.0375125 E \bullet 00$ \\
\hline 5 & $=1.7000000 E-06$ & $-1.2 \cup 7 a 079 E-n{ }^{2}$ & $0.19162755-08$ \\
\hline & 0. & ว. & lHIS PARAMETER WAS MELO \\
\hline & $3.030 \operatorname{cog} 0[-0]$ & 3. n365̄000E•01 & IHIS PARAmETER WAS WELO \\
\hline
\end{tabular}


FILE I, LIMPAT TALL, H PIAEI.

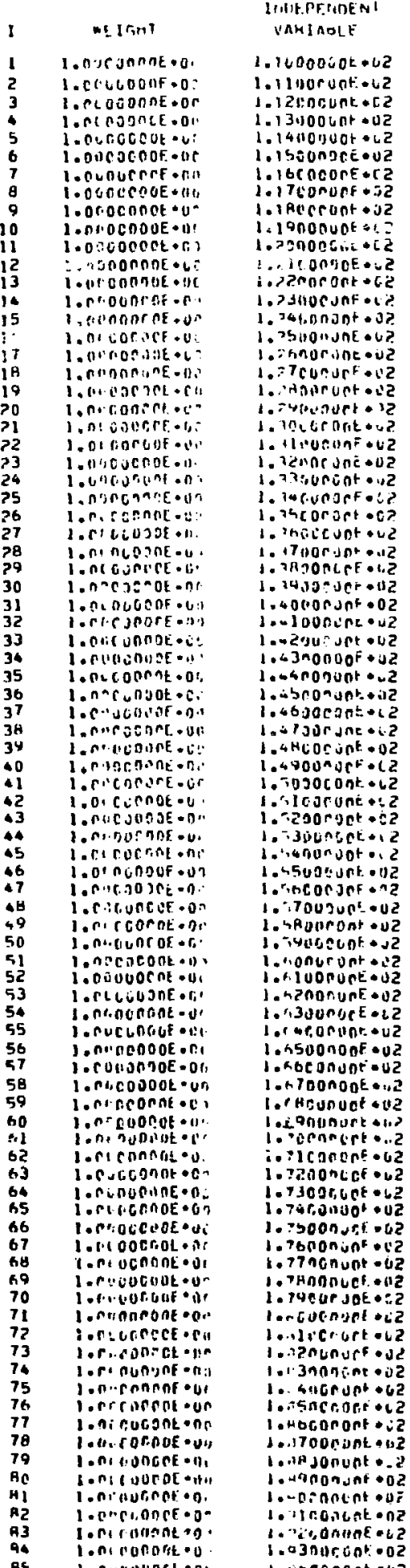

UEPEHUENT

VARTAGLE

3.54 I OOQE 00

$3.5450000 E \div 00$

$3.5400000 E+00$

3.536 TOOOE 000

$3.5330000 E \cdot 00$

$3.5600000 E+00$

3.56/noct.:.

3. 55 En $=$ LOE- 10

S. 34 COOCOL=0O

$3.54 \div 000 U E .00$

3.541 OOOUE +00

3.5400 COUE + 00

3,560 CPOAF. $\bullet 00$

3.57UnOOOE +00

$3,53 \times \cap O D U E$ - $\cup 0$

3., S4 כNUOUE - UO

3.543 OnOUE 00

3. S?UnOCOE + 00

3.54 P R NUUE - 00

$3.5 k$ incort +00

3.5 PrnOOOF $\bullet 00$

3.363 DOOnt. 00

$3.534 n 004 t \cdot 00$

$3.5130060 \mathrm{O} .00$

3.540 Oank 00

3.534 NRACE - 00

3.5 YOLOOE OOD

3. $570000 \mathrm{JE}$-0O

3.57GRODUE - 00

3. Si +0 COLE 00

$3.5, C \cap 000 E \bullet 00$

$3.5130 \angle O O E \cdot 00$

3.5 . PUU 0 O 00

$3.5400000 E \cdot 00$

3.5300OUUE + JO

3.5 SONDUOE .50

$3.5330000 \mathrm{~B}+00$

3.5 TSCกOUE O 00

3.56300006 .00

$3.5100000 E$ - UO

3.40 ! $U G U E+00$

3.512 O UUJE + 00

$3.401 \cap C 00 E-U 0$

3. bnbuoude. 00

3.510 nojut * 00

$3.5 ? 30$ nnUF -00

$3.40600011 E-20$

$3.493 \cap 00 \cap E \cdot 00$

$3.5200000 E=00$

$3.5430000 E \cdot 00$

3.5210000 - 00

3.521 तCOOE 00
3.520 NOOUE 00

3.521 OUUUE 00

3.521 OUUUE 00
$3.5 n+$ PCOOE
3.00

3.472 กOOOL 00

3.511 UUOOE 00

$3.53 ! 0000 E+00$

$3.530 n 000 E \cdot 00$

$3.5360000 E=00$

1. 443 3nnnF $\cap n$

3.b JInCuUE - CO

$3.553 \cap 000 E+00$

$3.53 Y \cap 000$ — 00

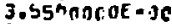

3.5500000 - 00

$3.5+2 n C 00 F * 00$

3.375 HOC UE $\bullet$ DO

3. 5 SONGCOE $\circ 0$

$3.544 n C$ OF $\bullet 110$

3.573000UE - UO

$3.5710000 E \cdot 00$

3.SAOG. CUCE -OS

3,5A3RDOOE - OO

3.SBS $1000 E \bullet U C$

3.563roOOE + J

$3.6 p 0 r 000 E \cdot 00$

3.500 NoCnE 00

3.563000UE - 00

3.6nSACOOE.0O

3.5AONODOE.00

3.5०BAOEUE - 110

3.07000COE.00

3.6. 4 ACOOE -00

3,053 BCOOE 00

3.h3JnGuUe - to

$10 / 25 / 74 \quad 17.62 .30$

CALCULATED

FUNCTIOCA

3.5367 BIE.00

$3.5367 A 31 E+00$

$3.5367831 \mathrm{E} 000$

$3.5367831 E \div 00$

.5367 31 $1 E .00$

$3.5367831 E+00$

3.5367 AIF 00

$3.5367831 E+00$

$3.5367 A 31 E 000$

$5367 B 31 E * 00$

.5367A31E*00

3.5367 AJIE.00

$3.5367831 \mathrm{E}+00$

$3.5367831 \mathrm{E} 000$

$3.5367831 \mathrm{E} \cdot 00$

$3.5367 A 31 E \circ 00$

\%367A31E 00

3.5367A.J IE 00

T.53678.31E.00

3.5367R31E.00

$3.5367 A 31 E+00$

3.5367 A31E. 00

3.5367R3IE.00

3.5367 A IE.00

3.5367A31E.00

3.5367A3IE - 00

$3.5367 \mathrm{HIE} \cdot 00$

7.5367A3IE-00

$3.5367 A 31 E=00$

3.9367A3IE.00

3.5367 AIE. 00

$.53678 .31 E+C 0$

.5367A31E-00

$.5367 A 31 E+00$

$5367831 E \cdot 00$

$5367831 E 000$

53 TA3IE*00

.536 - A31E.00

$.5367831 E+00$

$3.5367 A 31 E+00$

$3.5367831 E+00$

3.5367 ก31E $* 00$

$3.5367831 E .00$

$3.5367831 E .00$

3.5367A3IE.00

$3.5367831 E \cdot 00$

I. 5367 BIE.00

$3.5367831 E .00$

$3.5367931 E .00$

$5367931 E .00$
$3.536783 I F .00$

$3.5367831 E+00$

$.5367831 E .00$

$.5367831 \mathrm{t}+00$

3.5367B31F .00

3.5367A3IE 00

3.5367831400

3.536793IF. 00

3.5367A3IF .00

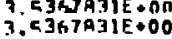

3.5367931f.00

$3,5367931 E+00$

$3.5367 A 31 E+00$

3.5367ajic.00

3.5367 a $16+00$

$7.53618315 \cdot 00$

$3,4367831 \mathrm{~F} \cdot 00$

$3.5377633 E=00$

$3.5003216 \mathrm{~F} \cdot 00$

3. $5437518 E \cdot 00$

$3.5476479 t \cdot 00$

$3.5524957 \mathrm{E}+00$

$3.457 \rightarrow 1670 \cdot 00$

$3.56315 A 7 \mathrm{E}-00$

3. $5690722 E \cdot 00$

7. $5753277 \mathrm{FE} \cdot 00$

$3.5818775 E \cdot 00$

3 GB $113 E .00$

$3.5957994 \mathrm{E} 000$

$3.4031220 E \cdot 00$

3. 1 1 Ch5BSE.00

3.61 U3916E.00

$3.6263050 F .00$

$3.45438365 \cdot 00$
UEVIATION

4.2168 ! $7 F=03$

8. $2: 5017 \mathrm{E}-03$

$.2168017 E-0.3$

$7.8311827 E-O C$

3. $7831183 \mathrm{E}=03$

$3.1216882 E-02$

$3.0216882 E=02$

$1.9210882 E=02$

$.2168817 E-03$

$1.22168 B 2 E-02$

. $2168817 E=03$

$.2168 B 17 E-C 3$

$2.9216882 E-02$

- 12168B2E- 52

2.216AB17E-0J

Q.216RHI TF-O

$6.2168+17 E-A 3$

$-1.07 b 311 \cup E-0$ ?

S. CIRAAI TE- $=3$

3.0216AK2E-D2

-1.478311 \&E = 0 ?

$2.6216 \mathrm{HBZE}=0$ ?

$-1.2783118 E-0$ ?

- 2.37431 l be- a?

3.2168817E-03

$-2.7831163 E-03$

$-1.778311 \mathrm{HE}=\mathrm{GP}$

-1.67 A311 $\mathrm{HE}-0$.

$-6.7831183 E-03$

$-2.2763118 E-[2$

$-2.0783116 E-02$

$-2.1783116 E-0$ ?

$-2.7763116 E-02$

Q.2166B17F-03

$-6,7831183 E-03$

$-3.678311 \mathrm{BE}=0$ ?

-3.78311 a $S E-G 3$

$-1.7831163 E-n 3$

$2.6216842 E-02$

2.0783IIRE-0?

$-3.978311 \mathrm{BE}=02$

$-2.4783118 E-02$

$-4.576311 \mathrm{AE}=0$ ?

$-2,87 \mathrm{BI} 1$ dE-C?

-1.878311 \&E-0z

-3.7831 / $8 \mathrm{JE}=03$

$-4.076311 \forall E-C 2$

$-4.3763118 E=n$

8.78311 $13 E-03$

6.21+8B17E- 3

$-1.57631186-0$ ?

$-1.5783118 E-05$

-3.278311 UE-E?

$-6.4783118 E-2$ ?

$-2.578311 \mathrm{BE}-\mathrm{C2}$

2. $1688173 \mathrm{E}-06$

$-6.7831163 E-03$

$-2.783)$ | $33 E-23$

$6.216 B A 17 F=r 2$

. IBJ1183E-n3

. E216H82F-n?

$.92) 6 B 825-2 Z$

921 $19825-02$

$5.2168 B 17 E-J 3$

3. 8 ह loHBZE-02

.921 GAB2E-0?

$0.2367277 E-03$

$3.267 \mathrm{~B} 402 \mathrm{E}=0$ ?

$3.3240221 \mathrm{E}=\mathrm{C} 2$

$3.7152070 E-0$ ?

$3 . C_{1}, 431 \mathrm{CE}-\mathrm{C} 2$

$2.7361755 E-C ?$

$-1.586 A 577 E-C O$

उe6927756E-02

2.0677796F -0?

- 1.6B7751 $6 E-02$

$1.02 A 46875=9$ ?

-7.790RABEF-03

- $.71220215=02$

$1.0341536 E=C$ C

6.0242 h46E- 04

$-1.3835734 t=03$ 




1.25 UOCUNE $\triangle$ U2

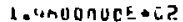
1. TroOn UnE + L 2 1. Jhagrupf +02 $1.090 \mathrm{C}$ :UNE $\$ 02$ C. OngRuge ou 2 $\therefore .10 \mathrm{CLONE}$-6? C. Zlonche - S? c. 3rullotelz . - unNunF or? C. 5.JUCUAE + U2 $\therefore$ b.) $0.1 \mathrm{nE}+02$ C. TUONTIOE + tis C. BDOJONE + IJZ C. - YJAOUnt - C2 CA I UUCONE -OZ $\angle 11$ nociot. $-1,2$ - 12 MOUUnE 9 , 2 C.130000n - il $C .130000 \mathrm{R}$ * II
$\angle .1450,10 \mathrm{NE}+02$ C. ISUONunE + jic C.1600000t-u2 C. 1711010CE - C 2 C.1HNONOCE +.2 C. 1911 UN UnE - J?

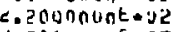
¿.PIDOnite 0 0 C. 22 JonunE Q U2 S. 3rungrtedz $2 .>450$ nunt 062 ¿.25nock ot - u? ¿.>ONOCUCE 02 $C .>700000 E \bullet 0 Z$ C. $>800000 E \cdot 02$ 2. $7900000 E+02$ C. $3000000 E .02$ C. $3100000 E$. LZ 2. 1200 NUCE $* i, 2$ c. 3390vuet. 22 C. 34 Cunice-ce c. 7500 nont $:$ is c.ionctiof ous 6. Pcurunf.jz c. The Crunt t 2 c. T4conuat ons $\angle 40$ COOLrit ceslconset.:

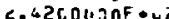
2.43 CCnicf $-j 2$ C.43rCnuCF $-J 2$ - 4 corvok C. SIlleriot * $\angle-46130 n c 0^{6}-02$ $\angle . .7$ ocot.nf $-c .2$ co Allonurt ouz $\therefore-D G(r)$ nt ous $x=-$ oguranf ou caingrupt oc

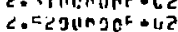
$c=5 j r a n d t a t s$

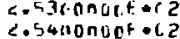


C. hEOTURE c.sliveurt ouz c. Throrurf $\rightarrow$ c i. Furctonf tis? cosousn jot $-\mathrm{u} 2$ c. Plogeunt is c. Fogonopt of C.43t.qrurt $0: 12$ c. i.4nuoinf - u2 $2.15 n 000$ p ous comononut ote 2.07 igpotat: $: 2$

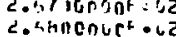
C.49:00 ror.t $\bullet 42$ c.7co0n'jnt * z collornaf iz c. Drofint. DIS C.73ugróf ouz 2. 74uOCGOE + 42 C. 75 100 J of + is c. $7(1)$ Cnoct - $t$ ? C. 77 F. OCUAE Q U? $\angle .7 H L O O O N F \circ 0 Z$ C. TYOGGUOF + iC
3.050 OOUE 00 $3.6420 C O O E \cdot O 0$ 3.ORUNCOUE 00 $3.0 R 40 C O C E$. OO $3.6 P 30000 E+00$ 3. 0 P0OOOOE - UO $\left.3.73^{7}\right) C O A t .00$ 3.713 nOUOE 00 $3.724 \mathrm{CCOOF}$.60 $3.7300000 E+6$ $3.72+n C O O E$ - 0 3.730 CCOOE - OO $3.7240000 E+00$ 3.7T? OOONOE 00 3.793 OCOUE 00 3.7aHCCOUE - OO


3.7RzONOUE 3.7900000E- 10 $3.7630000 E-00$ $3.8110000 \mathrm{t}-00$ 3. $80^{\circ} 0000 E .00$ $3.8300000 E \bullet 00$ 3.79 ! $000 E \cdot 00$ 3. $450000 \mathrm{E} 00$ 3.H61 OOOUE 00 3. H4SOCOUE - OO 3.854 AODOE + 00 $3.8640000 E+00$ $3.86000 \mathrm{OCE}+00$ 3.9 ก NOOUE + 00 $3.9030000 E+60$ $3.9,70000 E+00$ $3.8900000 E-00$ 3.885nO ONE +00 3.9050000E.00 $3.9670000 E+00$ $3.9220000 E-00$ 3.42 ' $O C O E \bullet 00$ 3. 94200011600 $3 .+7$ I CODUE 00 3.96n COOUE - OO 3.47 C nujak 00 $3.5420 G 0 Q E$. 00 3.942तOOUE - 00 3.93 PCOCE.0O 3.97 yndioot 00 3.97\% ruoet 00 3.94 ONULE 00 3. 9 G COGOE-OA $3.071 \cap 00 G E+00$ 3. CaUnOOOE OOO 3.95! OUOOE.00 3.95 UnCOOE +0 3.454 OCCOE. 00 3.96 " OCLGE 00 3.943 COOUE +00 $4 . c n '$ COOCE - OO 3.47 Y OOE 00 3.95 COOOE $=00$ 3.960NOOUE +UO 3.9AOROOKE +UO $3.9>40002 \mathrm{~F} \cdot 00$ 3.9 i 30000 E 00 3.46 inoubt - vo 3.972000 crt +00 $4.613000 \mathrm{CF} \div 00$ $4 . C 320604 E+00$ 3.974 ROOOE • OO $4.00 U 0 O 0 O E+U 0$ $3.9 ค 20000 \mathrm{E}+60$ AndGUUOE $3.9800000 E+00$ 4. U0O0OOGE * OO 3. पPa NOUUE • UO 3.964 AC OUE + 00 4. RRU UCOOUE - 00 - L TCOCOJE - 10 $3.933 \cap C O O E+00$ $3.9540000 E \cdot 00$ 3.943 तCC OE $\bullet 00$ 3.93 ? COOOE *00 $3.99{ }^{4}$ กC OOE OOD 3.963 AOOOE - VO $3.9610000 E \cdot C O$ 3. OAZ RUOUE + 00
$3.6426129 E+00$ $3.55 n 9795 E+00$ 3.45947055 .00 $4080734 E 000$ . . . $767766 E .00$ $3.6855 \mathrm{ABhF} \cdot 00$ $3.6946381 E .00$ $3.7033745 E \cdot 00$ $3.7123472 \mathrm{E} .00$ $3,7214058 E 00$ 3.7304800 .0D $3.7304800 E * 00$ $3.7395799 E+00$
$3.7486953 E+00$ 3.757 H $16.3 \mathrm{E}+40$ 3.766933 กE $* 00$ $3.7760355 \mathrm{E} \cdot 00$ .7951 37E 00 $3.7951137 E+00$ $3.7941575 E+00$ 3. .01) $1567 E * 00$ 3.A121011E*OC 3. $8209400 \mathrm{O} \cdot 00$ 3. 3A49BIE 00 3. $2556212 E \cdot 00$ 3.964004 TE.00 3. $2722528 E \cdot 00$ 3. ABก 35 I BE 400 3. ABBZA77E 00 3.म96 U453E ०00 $3.0036084 E \cdot 00$ 3.01095965 .00 $3.9180799 E+00$ $3.9249483 \mathrm{E} \cdot 00$ $3.9315414 E+00$ $3.0378330 E \cdot 00$ $3.9 ! 37924 E+00$ $3.4493840 \mathrm{E} \cdot 00$ $3.0545641 \mathrm{E} .0 \mathrm{C}$ $3.9592778 E \cdot 00$ 3.06345145 .00 $3.0634514 \mathrm{~F} .00$

3.06965865 .00 3.07n9207E.00 $3.07 n 9207 \mathrm{E} \cdot 00$ 3.97 ก $9207 E+00$ .9.97C9207E+00 $3.97 n 920 / F+00$ $3.0709207 F+C O$ $3.9709207 E+C 0$
$3.97 n 9207 E \cdot 00$ $3.97 n 9207 \mathrm{E} .00$
$3.0709207 \mathrm{~F} .00$ 3.97 r $9207 E+00$ $3.07 .9207 E+C O$ $3.97 \mathrm{C} 9207 \mathrm{E}+00$ $3.0769207 \mathrm{~F} \cdot 0 \mathrm{C}$ 3.97 ก $207 \mathrm{~F}+00$ $3.0704207 \mathrm{f} 00$ $3.9 \ln 9$ P. $07 \mathrm{C}^{\circ}+00$ $3.97 \cap 9207 E \bullet 00$ 3.97 ก $207 f .00$ $3.0709207 \mathrm{E} \cdot 00$ $3.97 \pi 5207 E+00$ 307092075000 3.970920 $3.07 \mathrm{C}^{3} 0 \mathrm{JF}+00$ $3.0709207 \%+00$ $3.9769207 \mathrm{E}+00$ $3.0709183 E+100$ 3.07 $04999 \mathrm{C}+\mathrm{CO}$ $3.7704555 \%+00$ $3.0751797 E+00$ $3.970,0642 \mathrm{E} \cdot 00$ $3.0705075 E+00$ $3.77 \times 30495.00$ $3.9700530 E+00$ 3.96974RGE + 00 3.9693490 . 00 3.9693 A9 $3.9689717 E .00$ $3.9684945 \mathrm{E} \cdot 00$ $3.9679551 E \cdot 00$
$3+9673516 E \cdot 00$ 3. $7666824 E+00$ $3.9659457 \mathrm{E} .00$ 3 3651400E.00 $3.9442641 E \cdot 00$

$1.3387_{0} B S E=0 ?$ $-8.979503 \mathrm{AE}=0.3$ $2.0529543 E=02$ 1.3926552E-j2 $6.2233111 E-03$ -5.56 A5SGZE - 1.3 $4.456187 \mathrm{GE}-32$ $9.6754605 E-03$ $1.1632784 \mathrm{E}-77$ 1.504 6.5 $0.480 J 392 E-C 3$ $-9.57587 / 6 E-03$ $-2.4695243 E-n ?$ $1.9183671 E-02$ $2.0060956 E-n 2$ $1.2966514 E-02$
$-2.3113654 E-02$

$1.642533 \mathrm{hE}-23$ $-2.0156728 E=02$ $-1.1010862 E-03$ $-1.2986007 E-02$ $0.2172920 E-03$ $4.1498132 E-\cap 2$ 1. $0985116 E=0$ ? 5. $3788284 E-03$ -1.9004730E-0? -! H252772E-02 $-1.1351631 \mathrm{E}=02$ $-2.2287704 E-0$ ? 


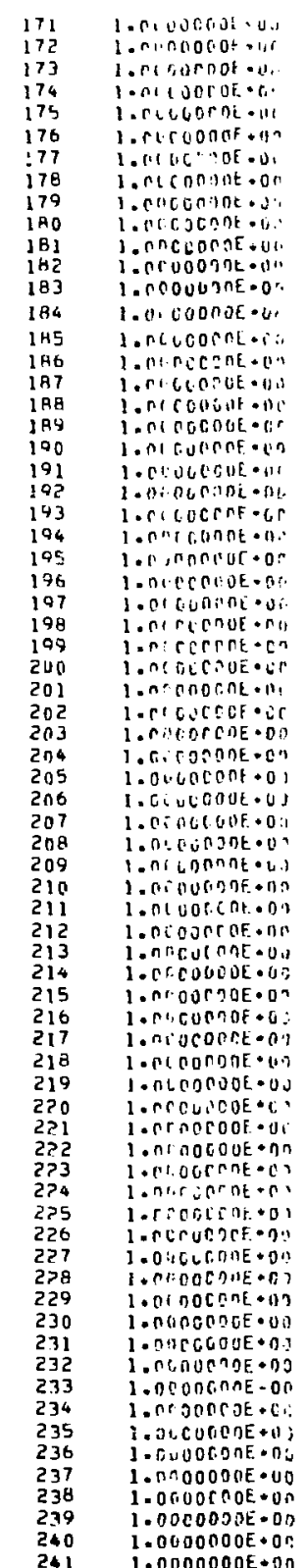

s. veunirtis

c.inutinnter ¿. shoulat o va $\therefore$ ajionactos - 16100ilint c. 1.5rocuat + caterandint $=0 \mathrm{c}$ $\therefore$ a Pannlant 0 ? $\therefore$ : HOCOInE=UZ $\therefore$ ovoriate $\therefore$ iroounf +ue C.:200000F 02 2. 3corunfo.j c. $34 t=6 \mathrm{cht} \cdot 02$ C. I5tiosunf.u? c.thronont 12 c.JTuUrunt ou C. JRrocunf of 2. 39 rencet:iz

3 OLCOOnF U i. Jionurt o o J. $\operatorname{scogant:az}$ J. 3ronunt - U? 1. "usiantecc $\therefore$ jecoict

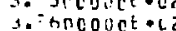


ב. Ho:Gunito A- te onunt -12 A I wOOnORE - i i. 1 ircelint er A.jorocunf o 9.ibogant.os

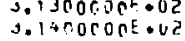
31500 ODE - S $\$ .16000 \mathrm{Jit} \cdot 02$ $9.17500 \mathrm{st} \cdot 0$ ? $\$ 1$ bugurtac S. 19000 Jot ou?

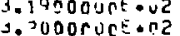
J.? InONOnE - U? 3. 3 ? CON unt 42 3. 3nurgrs.02 $3.24007 \mathrm{ut} \cdot 0$ ? 3.T ST JCUAE-02 3.>6OUnJal-02 3. $>$ C CONGRE UZ

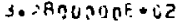
I. PQUUOURE ० O2 3. 3 J J OCOEE - 62 3. ग100OUAE + La

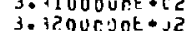

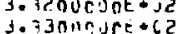
3. 74 3nOUOE + TC $3.359 u c u r 5+32$ 1. $760 \mathrm{crcot}+0 \mathrm{C}$ 1. 3 CCONCE - D2

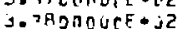
3. 39000UCE +EC $3.390000 E+C 2$
3.4010000 $3.40000006+02$
$1.610000 \mathrm{CF} \cdot 32$ $3.4200 \cap J C E+02$ 3.430 ) त 3 NE . 02 $3.44100 \cup N E$ - 02 3.4500 ONE. 02 3.4500 ONE.0Z $3.406000 \mathrm{NE} \cdot 02$ $3.4800000 E+02$ $3.4900000 E+02$ $3.5000000 \mathrm{E}+02$
3.9716 inout $* 0$ $4,2134006 t+00$ $3.44+C$ UOUF + 10 $3.4 a \rightarrow 0 \cup O U E * U D$ $+.1>1060$ t +60 3. 910OBDIE COO 3.7HDOLUUt - On 3. 9 RDOCSUE. 00 3.95 inCuUF. 00 3.44 inGOLt - UO 3. 5 jE 10 UUE. 00 3.960 COOOE UJ $3.4710000 t+00$ $3.922000 C E+00$ 3.542 RUUCt -00 3.943 InOCE - 00 3.9× 3 NOOOE +00 $3.47^{4}$ UCOUE $\rightarrow 00$ 3.402000 OE +00 3.411 ONOUE + 00 $3.03 \$$ INOOUE + D 0 3.97 ! $0000 \mathrm{C} 00$ $3.97411000 E \cdot 00$ 3.533 COCUE +00 $3.9730006 . E+00$ $3.97 \times 0300 E \cdot 00$ $3.9400000 \mathrm{E}+00$ S. HAI0OOOE 00 3.939 กCOCE $० 00$ 3. $4310000 E \cdot 40$ $3.57 O N O U D E+O D$ 3.941 CCCUE.00 J. 9 ก $10000 E 000$ 3. HQ1 กOOOE.0O 3. $51700000 \mathrm{E} \cdot 00$ 3. $52 \cap C D O E \cdot 00$

$3.65+0000 \mathrm{E} \cdot 0 \mathrm{O}$ 3. 8 ímague 00 3. $42^{4}$ C COOOE +00 3. $8640000 \mathrm{E}+00$ $3.8700000 E+00$ 3.93Y $0000 E .00$ $3.8,4 n 000$ E 00 $3.8550000 E+00$

$3.0730000 E+00$ 3. H1 $100000 E+O 0$ 3. E31000OE.0O 3. $A \cap O 0 O O O E+J O$ 3. $6 \bar{r} 29000 E \rightarrow 00$ $3.8 \cap \ln 000 E+00$ 3. $8>10000 E+00$ $3.8000000 \mathrm{UE}+00$

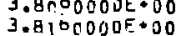
3.810 COJDE 00
$3.8 n ' C O O U E+00$ 3.8100DUOE 00 $3.8100000 E+00$ $3.7910000 E .00$ $3.7830000 E$ t $3.8700000 \mathrm{E}$ $3.6700000 E$ ० 3. $800000 U E+U D$ 3.771000UE - UO $3.7040000 E * 0$ I $3.7910000 E+U 0$ $3.8220000 E$. UO $3.7400000 E+00$ $3.791 \cap 00 O E+00$ 3.7RYCCOOE +OO $3.76 Y 00 C O F+00$ $3.75 Y 6000 E+00$ $3.6020000 E+00$ $3.7710000 \mathrm{E} \cdot 00$
3. Th 33160t 00 3.9022965 t. 00

7.7012 r.20F.00

$3.2000342 E \cdot 00$

$.95979045+00$

7. $0574704 \mathrm{P} \cdot 00$

7. 7365736E-00

$7.9565795 \mathrm{E} \cdot 00$ $3.9530477 \mathrm{E}-00$

$3.0514179 \mathrm{E}=00$

$3.9497096 \mathrm{E} .00$ $3.9479274 E+00$ $3.9460575 E+00$

$3.0441134 \mathrm{E} \cdot 00$

$3.9420909 E \cdot 00$ 3.9399 R $9 t+00$ $3.037810 \mathrm{OAE} .00$

$3.9355539 \mathrm{E}+00$ 3. $933219 \mathrm{hE} \cdot 00$ $3.03 \mathrm{nBOA5E}+00$ $3.9783211 F .00$ 3. $97575 \mathrm{AZE}+00$ $3.9231>05 E \cdot 00$ $3.020 .4091 E \cdot 00$ $3.0) 70247 \mathrm{E} \cdot 00$ $7.01476 R 7 E+10$ $3.0117421 \mathrm{E} \cdot 10$ $3.9068464 F+00$ 3.9057 A $30 E \cdot 00$ $3.9026535 \mathrm{E}+00$ $3.9994597 \mathrm{E} \cdot 00$ 3. $9962034 \mathrm{~F}+00$ 3. $A Y 28$ CAE 00 3.RAQ5121E.00 3.RA95121E.00 3. $A 825987 \mathrm{E}+00$ 3. $9: 90656 E+00$ 3. $A 754 R 61 E \div 00$ 3.RT18037E.00 3. $9682 \cap 30 E+00$ $3.9692 \cap 30 E+00$
$3.2645089 E+00$ 3. $A 507877 E+00$ $3 . \$ 570483 E+00$ 3. $.533051 E+00$ 3. $4495619 \mathrm{E} .00$ $3.9458187 \mathrm{E}+00$ $3.4658187 E+00$
$3.0420754 E+00$ $3.8383322 E * 00$ $3.8345 B 90 E \cdot 00$ $3 . A 3 r, 845 B E \cdot 00$ 3. 22710265000 3.R233593E.00 $3.22335935 \cdot 00$
$3.81901615 \cdot 00$ 3.81961611 .00
$3.2158729 E \cdot 00$ 3.R121?97E.00 3. $8083864 \mathrm{E}+00$ 3. $2046432 E \cdot 00$ 3.PON900NE*00 $3.7971568 E \cdot 06$ $3.7936136 E+00$ $3,7896703 \mathrm{E}-00$ $3.7859271 \mathrm{E}+00$ 3.7821 A39F +00 $3.7784607 E-00$ $3.7746975 \mathrm{E}+00$ $3.77 \mathrm{G} 9542 \mathrm{E}+00$ $3.7672110 \mathrm{E}+00$ $3.7634678 \mathrm{E}+00$ $3.7597246 \mathrm{E} \cdot 00$ $3.7559813 E+00$ $3.7522381 \mathrm{E} \cdot 00$
2.76, $1108 t-n ?$ $\because .7263944 \mathrm{E}-1$ ? उ.9647प? PE$0.220445, \mathrm{VE}=07$ $-4.14 l, 354 E-7 ?$ 1.19264 USE - ? ? $1.14 C+1401 E-17$

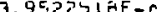
.

-4.4178 $1.1799633 E-[7$

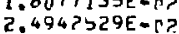
$-2.2113445 E \times n ?$ - 9.0644 al $3 E-05$ $3.0 \ln 1334 E-C 3$ 2.71B9205E =C? $3.4461120 E=03$ $-4.1219614 E=U 7$ - 1 . 3 ACE 4 \& 4. . THERS UE- 3 $1.12417+7 \mathrm{E}-0 ?$ $8.7945 \cap 32 E=C 4$ $1.2541964 \mathrm{E}-1.7$ $1.537527 \mathrm{SE}=0$ ? $2.4231332 E-n ?$ 3.t157891E-0? - 1. 1846393E-0? $3.3217012 E=n 2$ 2.6346501E-C? $3.654 C 326 E=0 ?$ $4.474657 Y F=C$ ? $0.1131 \cup 51 E-[3$ $1.4278752 E-03$ 1.91E16USE- 03 $-3.0509660 E-[?$ $-2.0065614 E-n$ ? -3.846605 dE - C? $-4.7 B+3743 E-C>$ -4. 2029 HBUE- 03 $1.3491132 \mathrm{E}-0$ ? -2.178760 तE-U? $-4+3048330 \mathrm{E}-\mathrm{C2}$ $1.6948922 E-C 3$ $-1.656)$ B86E-02 - $3.5818664 E-0$ ? $-1.1075443 \mathrm{E}-\mathrm{C}$ ? $-3.2332221 E-02$ $-1.2588999 \mathrm{E}-12$ $-2.9845777 \mathrm{E}-\mathrm{C7}$ - $0.1025555 \mathrm{E}-0 \mathrm{C}$ TE $-O B$ $-1.7359334 \mathrm{E}-0$ ? $-3.6161125 E-n 3$ $=8.6728903 E-07$ $-2.1296685 E-27$ $1.6135532 \mathrm{E}-\mathrm{n} 3$ $-2.3643225 E-27$

$-1.5900003 E-02$ 3.084321 9E-O2 $1.4586440 \mathrm{EE}-02$ -1.467 1 $333 \mathrm{EE}=0$ ? 8.072883BE-C3 $8.8161055 E-03$ $4.3559327 \mathrm{E}=0 ?$

$-3.4697451 E-? ?$ $1.0045771 \mathrm{E}-02$ $2.1788993 E-02$ $5322143 \mathrm{E}=03$ $9.2754361 E-03$ $4.601865 B E-02$ $1.8761880 \mathrm{E}-02$
GEIGHTFO VAPIANCE =

READ INPUT 
17.42 .71 Stimit

17.42 .51 WIPA ATE

17.4201 g.1U15

17.62 .71 s(lim)t

$17.42 . ? 2$ SUIDLATE

$17.42 .=$ ? SLIMTH

17.42 .52

$17.48,3$

$17.62 .7 ?$

17.62 .75 S1JM1N

17.42 .77

17.42 .78

17.42 .78

17.45 .97 8U4

17.62 .72

17.42 .37

17.62 .33 SUPLATE

$17.42 .730 \mathrm{Cct} 36$

17.42. 9 1 HIA

$17.42 .>$ SnIIP.

$17.42 .>9$ ocrt 39

17.42 .79 ect 46

17.42 .75 gunitim

$17.4 \bar{c} .25$

17.42 .39

17.42 .25

$17.62 .390^{\circ \mathrm{Cr}^{\circ}} 41$

17.42 .25 SUMIR

17.42 .75

17.45 .25

17.42 .05

17.42 .55 oct 42

17.43 .71 \$11M

17.42 .50 CRHFUC

$17.42 . \mathrm{C}^{1}$ - CCP 43

17.45 .51 - $\mathrm{CCH}$

17.45 .51 sinith

$17.42 .=1$

$17 .=2 \times 1$

$17.42 .{ }^{\circ} 1$

17.42 .51 SUMI

17.42 .51

17.42 .51

$17 .+\ldots 1$

17.45 .51 SUH 1 i

17.42 .51

17.42 .51

17.42 .51 sunth

17.62 .51

17.42 .51

$17.42 .=1$

$17.42 .0 !$ SUMTK

17.42 .01

17.4201

17.4201

17.420 . 1 SUMIR

17.42 .51

17.42 .51

$17.42 .=1$

17.42 .01 SUNTK

17.42 .51

$17.42=1$

$17.42=1$

17.42 .51 SUMIF

$17.42 .=1$

17.42 .51

$17.42 .=1$

17.42051 SUNIP

$17.42,51$

17.42 .51

17.42 .51

17.42 .51 SUMI

17.42 .51

$17.42 .=1$

$17.42 .=1$

17.02 .51 BUMIR

$17.42 .=1$

$17.42 .=1$

$17.02=1$

17.42.51 sumin

17.42 .51

17.42 .51

$17.42 .{ }^{\circ} 1$
IPPUTCUK FILS SET OFENEU, HUFFER LFNGTH 3320008

-EALITNA IAPUT

INUTEXT FILE SET OFERED. BUFFER LFNGTH $=320008$

IPUTSCR FILE SFT CPEAEU. UUFFER LFNGTH = 320008

"IECK STRULTUME EMANGED

IJPU!SCD CLOSE U

1024 READS 1554 WHITES

JPUTEAT CLUSEU

o SKIPS

2 OISK READS
2 OISK WRITES

(: REALS

D WHLTES

. P1)TCUK CLOSEU

225 REAOS

R3 WRITES

-PUATING lS CUMDLETE

1 DISK WRITES

SH UN IC $=5 \cdot I=$ CONDII E)

- 1tlu lemgita is - n60470

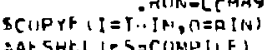



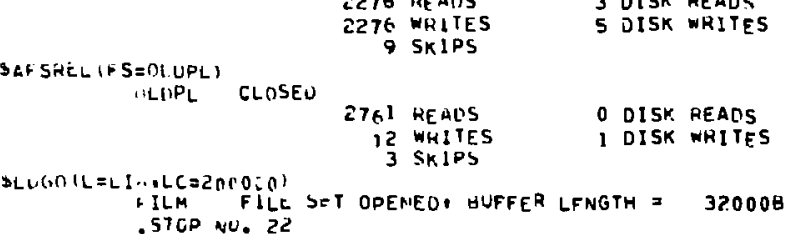

MAX LEN $=151678$
$=435378$

GUF LEN $=320008$

FSET LEN $=122338$

MAX LEN $=122333$

LCM SPACE =

DEV = DISKC

IF. OF INFIHMATION UN F LLESET DUCE

$.57 C P$ nu. 22

CCU CLOStU

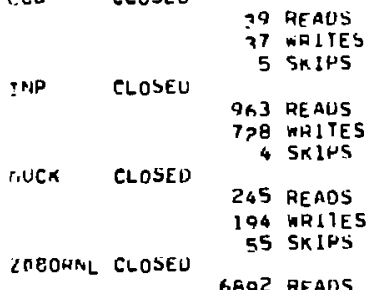

O DISK HEADS

BUF LEN =

FSET LEN :

D DISK HEADS

3 DISK. WHITES

LUTF LEN $=$
FSET LEN

MAX LEN =

5 DISK READS

4 DISK WKITES

BUF LEN -

FSET LEN

16 DISK READS

O WHITES

FSET 1 CLOSEU

I SKIPS

O DISK WRITES

BUF LEN

FSEI LEN $=$

$32000 \mathrm{~B}$

3240678

MAX LEN $=3240678$

2 DISK READS

676 REANS 6890 WRIIES

ZOSLSUE CLOSEO

14 $5 \times 1 P 5$

17 DISK WRITES

SET LEN $=3240678$

45 HEADS

O HMITES

1 SKlPS

1. CCO Clostu

c REAUS

22 WHITES

TEMI CLOSED

256 REAUS 256 WKITES

1 SRIPS

FSET4O CLOSEU

35 REAUS

35 WHITES

NEWPL CLOSEO

I SKIPS

I OISK AEADS

0 DISK WRITES

BUF LEN = $32000 B$

FSET LEN E 161779

MAX LEN $=161778$

- DISK HEADS

BUF LEN :

FSET LEN -

$32000 \mathrm{H}$

O DISK WRITES

MAX LEN E

- DISK REAOS

I DISK WHITES

HUF LEN

FSET LEN

MAX LEN =

O DISK HEADS

BUF LEN =

FSE T LEN =

MAX LEN =

1 DISK WHITES

RUF LEN

2 HAT READS

2797 WHIIFS
G SKINS

TIN CLUSEU

- DISK READS

FSET LEN =

MAX LEN =

52 REAOS

45 WHIIFS

THIN CLOSEO

22 HEAISS

$7 ?$ WHITFS
1 SKIPS
- DISK READS

5 DISK WHITES

UUE LEN *

MAX LEN :

O DISK HEADS
1 DISK WHITES
BUF LEN

FSET LEN :

MAX LEN :
TYPE $=5 T$

AD 1 SP = NONE

$1000 \mathrm{~B}$

$256 \mathrm{~B}$

100008
24348

50644

10008

16239
16238

3240678

1368

320008

320008
24726

TYPE $=5 T$

ADISP: NONE DEV = DISKC

321004

TYPE $=5 T$ ADISP = NONE DEV a DISKA

TYPE * ST

$\triangle D I S P=$ HONE

DEV = OISKA

TYPE $=5 T$

ADISP = HONE

DEV DISKA

TYPE $=5 P$

ADISP- NONE

DEV = DISKA

TYPE = ST

ADISP = NONE

DEV = DISKA

TYPE $=S P$

ADISPE NONE

DEV = DISKE

TYPE = ST

ADISPE NONE

TYPE = $5 T$

ADISPE NONE

DEV = DISKC

TYPE = ST

ADISP = NONE

OEV D DISKC

TYPE = ST

ADISP = NONE

DEV = DISKA

320008

$16521 \mathrm{~B}$

TYPE $=S T$

ADISP = NONE

DEV = DISKA

$3200 \mathrm{OH}$

120678

120678

TYPE $=S T$

AOISP: NONE

DEV = DISKE 


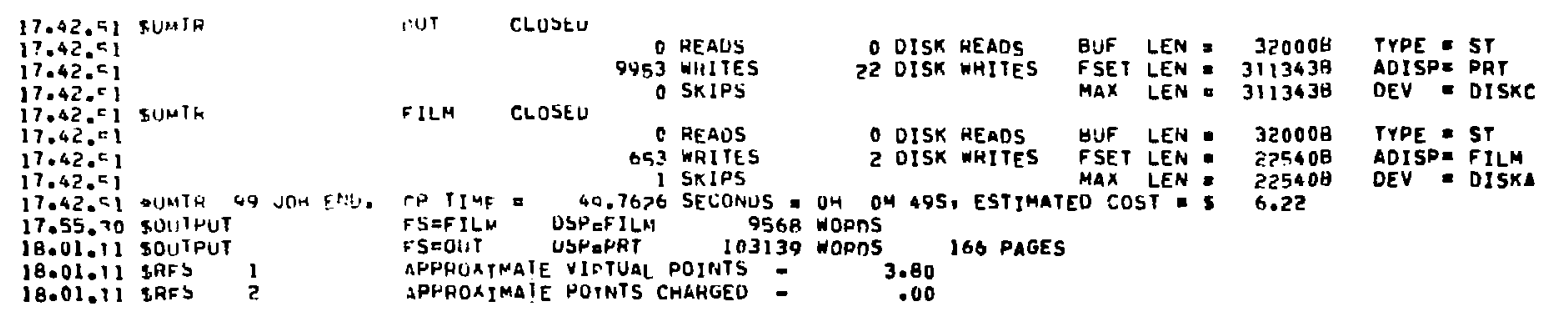

COMPIETE ZORHEY IVG 3

FILE 1, LIIIEAR TAIL, R FIYED

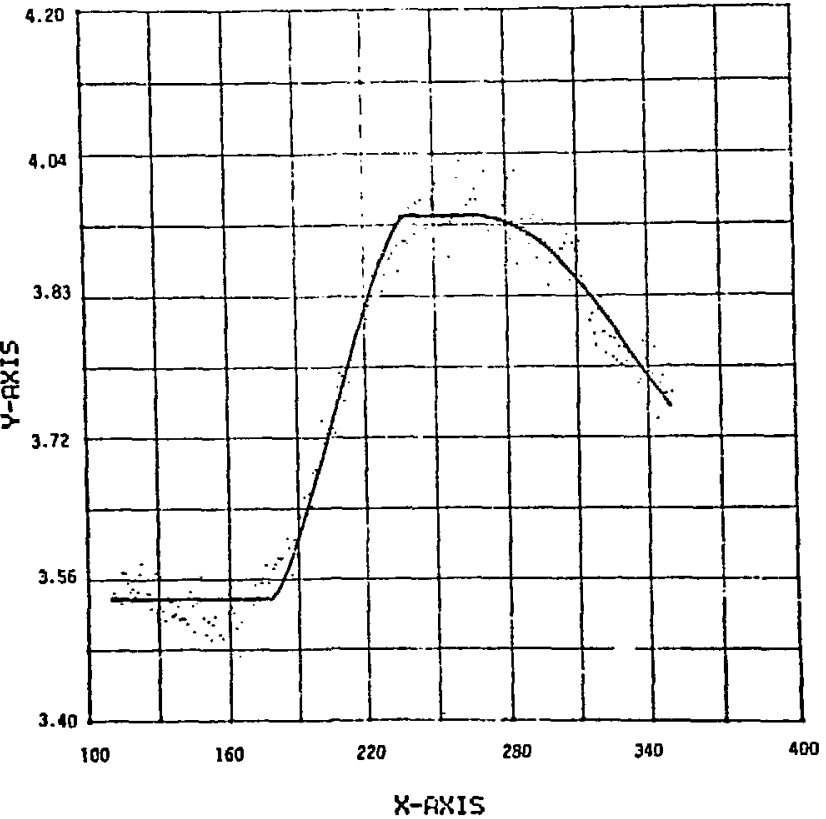

FILE 2, LIMEAR TAIL, R FIYED

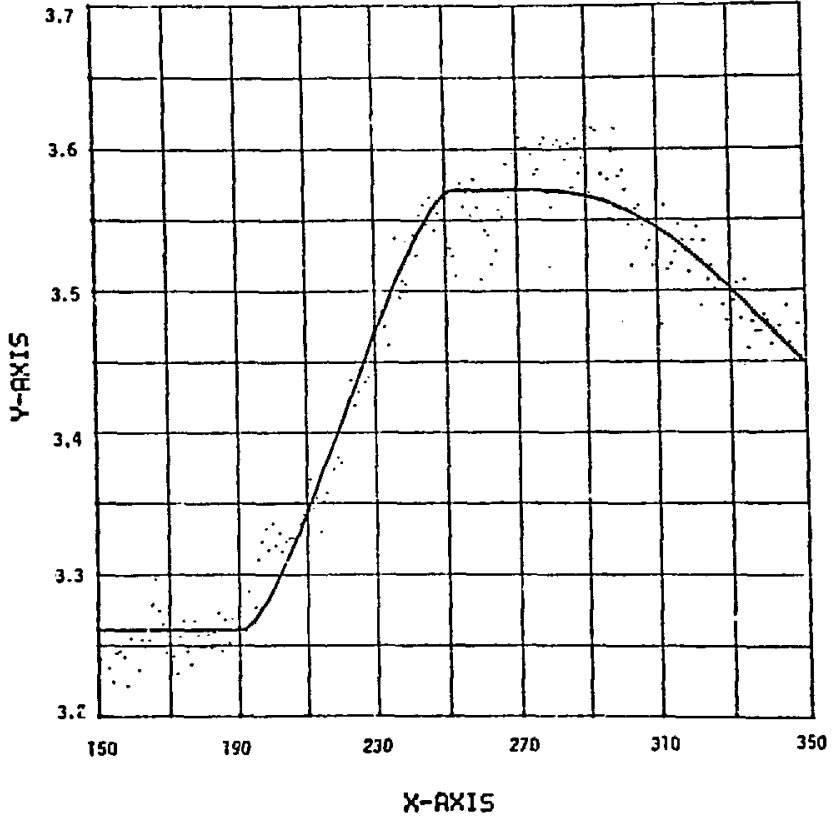

FILE 3, LINEAR TRIL, R FIYED

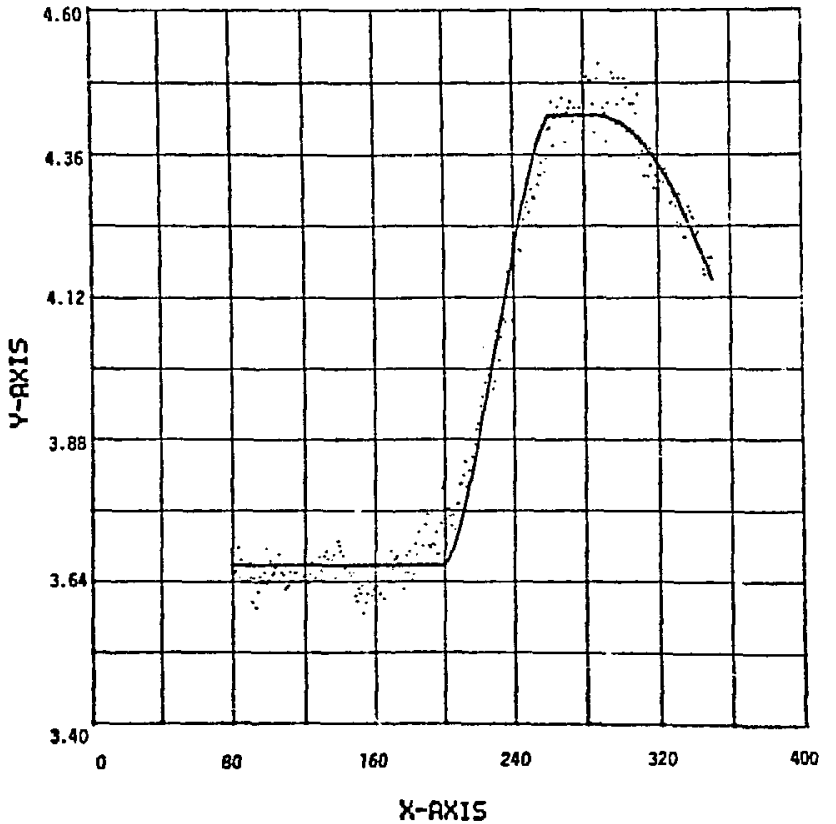

FILE 4, LIMEAR TAIL, P FIYED

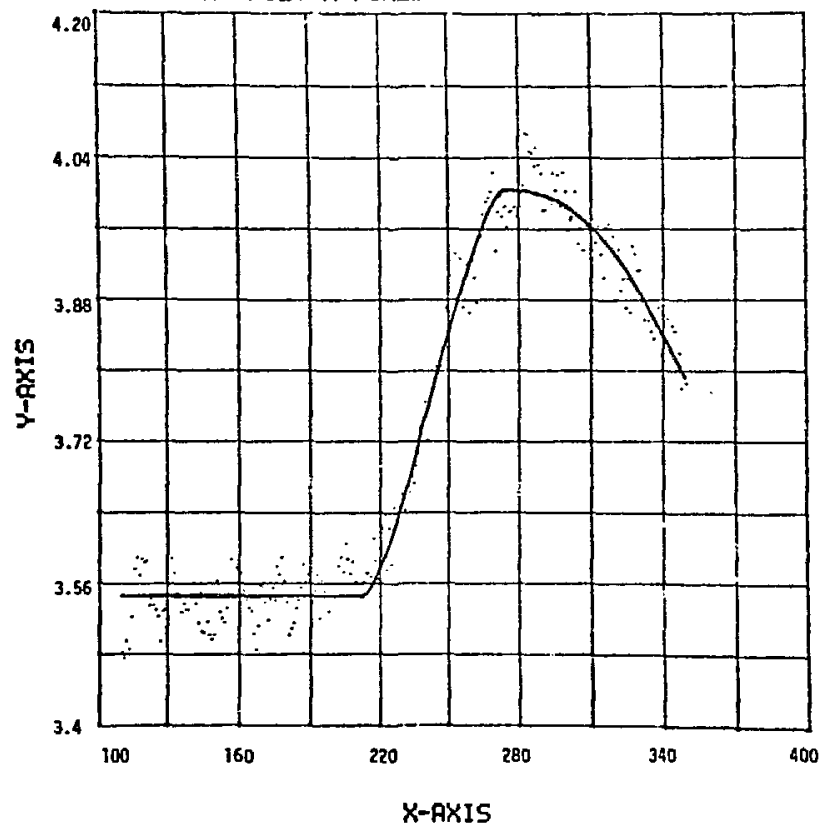


FILE 5, LIMEAR TAIL, R FISED

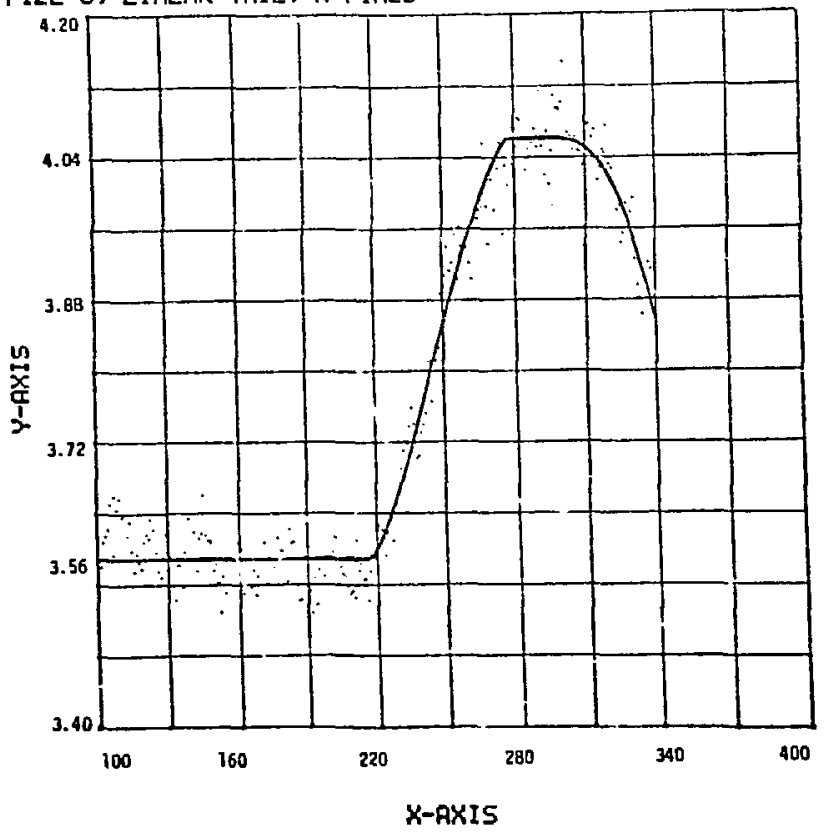

FILE 6, LINEAR TAIL, R FJYED

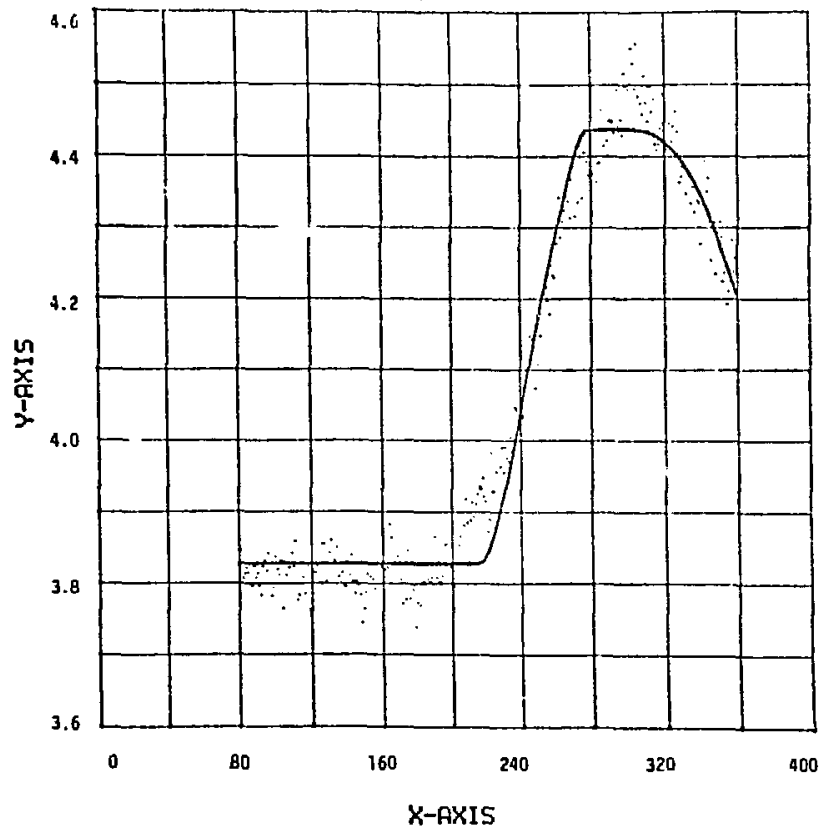







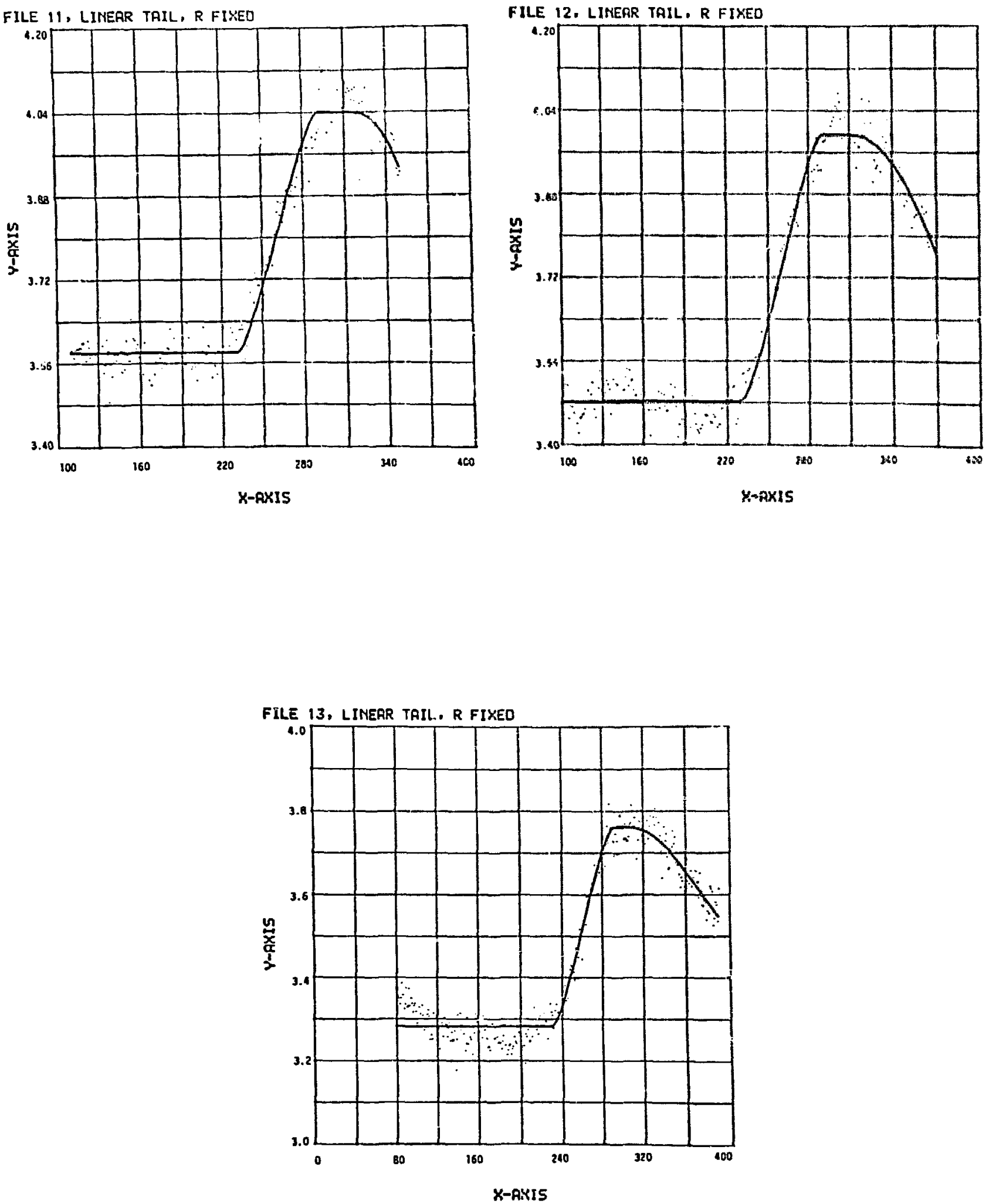

\# US GOVERNMENT PAINTING afFICE 1975-677.343/9 